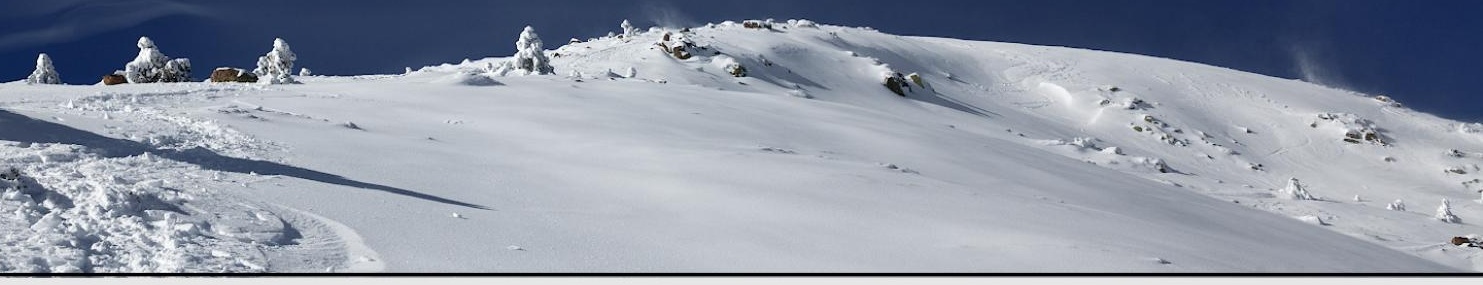

\title{
Predicción de aludes (3 casos)
}

\author{
María PALOMO SEgOVIA \\ Centro Nacional de Predicción (CNP), Agencia Estatal de Meteorología (AEMET) \\ JuAn ANTONIO FERnÁNDEZ-CAÑADAS \\ Observatorio de Navacerrada, AEMET
}

JuAn JosÉ RodRíGuez VELASCO

Delegación territorial (DT) Cantabria, AEMET

Contribución de: Alberto Fernández Matía

Área de Técnicas y Aplicaciones de Predicción (ATAP), AEMET

Así pues, declaro que es enemigo de la Naturaleza el hombre que no considera las altas montañas dignas de largo estudio. Es cierto que las partes más elevadas de los más altos picos parecen estar por encima de las leyes que rigen nuestro mundo de abajo como si pertenecieran a otra esfera. Allá arriba, el efecto del sol que todo lo puede no es el mismo, ni el del aire, ni el de los vientos. Allí la nieve es eterna...

Carta a su amigo JAMES Vogel (1541) - CONRAD GESSNER, Naturalista suizo, 1516-1565

Los aludes son fenómenos adversos para las actividades en montaña, con riesgos e impactos variados. A caballo entre lo meteorológico, lo nivológico y lo puramente geográfico, la predicción de aludes es un reto en el que el enfoque multidisciplinar adquiere importancia capital. En este capítulo presentamos la predicción de aludes intentando acercarnos a ese enfoque multidisciplinar, ahora con apoyo de los sistemas de predicción por conjuntos, para investigar el valor potencial que puede aportar la predicción probabilista en un tipo tan específico de predicción como es la de este fenómeno de los aludes. Abordando tres casos distintos correspondientes a tres tipos diferentes de alud intentamos también abarcar un amplio espectro de fenomenologías.

Palabras clave: sistemas de predicción por conjuntos aplicados a la predicción de corto y medio plazo, predicción probabilista, predicción de aludes, aludes de nieve reciente, aludes de placa, aludes de placa húmeda.

Imagen parte superior: nubes orográficas. Dos Hermanas (2276 m), Macizo de Peñalara (Madrid), hacia el noroeste, 24 de enero de 2014 a las 15:39. Fotografía de José Antonio Quirantes Calvo. 


\subsection{Introducción}

Las zonas de montaña presentan, por su relieve y topografía, una exposición especial a ciertos fenómenos meteorológicos adversos, entre los cuales se puede destacar el peligro de desencadenamiento de aludes, que puede llegar a ocasionar pérdidas humanas y un fuerte impacto económico.

España no presenta, en general, un peligro elevado de desencadenamiento de aludes, sin embargo, el número de víctimas por este fenómeno se ha ido incrementando en las últimas décadas.

Un alud es un desplazamiento rápido de una masa de nieve por la ladera de una montaña.

Una zona de aludes es una superficie sobre la cual se producen aludes de forma periódica. Dentro de una zona de aludes pueden distinguirse tres partes [17]:

Zona de salida. Zona donde la nieve se pone en movimiento.

Zona de trayecto o transición. Zona por la que transcurre el alud.

Zona de llegada o de depósito. Área en la que la nieve queda detenida.

La Comisión Internacional de Nieve y Hielo (UNESCO) estableció, en 1981, una propuesta de clasificación de los aludes según sus aspectos morfológicos y sus factores genéticos. Esta clasificación tiene en cuenta el volumen y las características de la nieve y las características de la salida, del trayecto y de la zona de llegada [17]. En esta clasificación se establecen tres tipos de aludes [7]:

Aludes de nieve reciente que se caracterizan por que la nieve que se pone en movimiento suele ser seca y fría y presenta una cohesión muy débil.

Aludes de placa que suelen presentar una salida lineal con una cicatriz clara y cuyo recorrido puede estar jalonado de bloques de formas tabulares y de tamaños variados. Estos bloques aparecen también en la zona de depósito.

Aludes de fusión o de nieve húmeda que se desencadenan en mantos de nieve compuestos por nieve con un elevado contenido en agua líquida. El desencadenamiento de aludes de fusión está directamente ligado a la presencia de agua en forma líquida dentro del manto nivoso.
La probabilidad de que en un área se desencadene un alud en un momento dado depende de dos tipos de variables:

Variables relacionadas con el terreno. Entre ellas están la altitud, la pendiente, la morfología y la rugosidad del terreno, la vegetación existente, y la orientación.

Variables meteorológicas y nivológicas. Se caracterizan por variar con el tiempo y son la precipitación, la temperatura, el viento y el estado y evolución del manto nivoso.

Las variables relacionadas con el terreno varían poco con el tiempo y, por lo tanto, pueden ser cartografiadas para aportar información persistente en el tiempo. Combinando algunas variables fisiográficas podemos elaborar modelos cartográficos de áreas especialmente favorables para el desencadenamiento de aludes que se pueden validar a partir de datos de aludes reales [1]. La mayoría de estos modelos utilizan como variables la pendiente del terreno, la presencia o ausencia de vegetación, la orientación de la ladera y la morfología y rugosidad del terreno. Como resultado se obtienen cartografías en las que el terreno se clasifica en distintos niveles de peligro de desencadenamiento. En la Figura 45.1 se muestra, a modo de ejemplo, un modelo cartográfico en el que se clasifica el terreno de un sector del macizo de Peñalara en la sierra de Guadarrama de la Comunidad de Madrid, en cuatro niveles de peligro de desencadenamiento de aludes. Este modelo se ha comparado con datos reales de aludes y, como resultado se ha observado que más del $95 \%$ de aludes observados se han desencadenado en zonas con un nivel alto o muy alto de peligro de desencadenamiento.

Las variables meteorológicas, sin ser las más importantes en el desencadenamiento, son relevantes en tanto en cuanto presentan una gran variabilidad temporal y condicionan el momento del alud. Las más importantes son la precipitación, la temperatura y el viento.

Las precipitaciones en forma de nieve aumentan el espesor del manto dando lugar a un incremento en el peso de éste. Cuando las precipitaciones son líquidas también producen un aumento en el peso del manto si quedan retenidas en él y, además, facilitan la fusión del manto si la temperatura de las precipitaciones es elevada. 


\section{CLASIFICACIÓN DEL TERRENO POR NIVEL DE PELIGRO DE ALUDES DE PEN̄ALLARA}

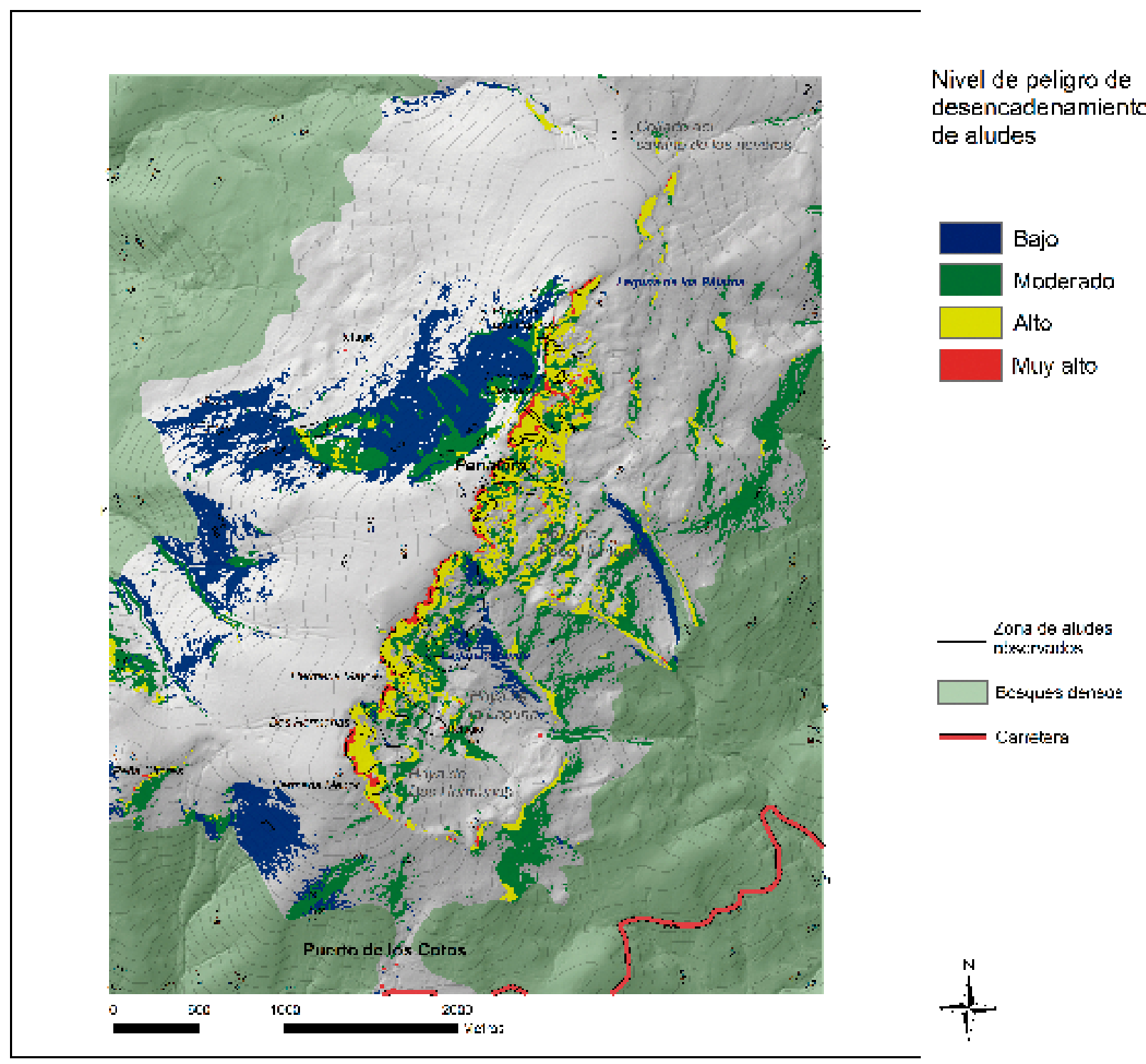

Figura 45.1: Clasificación del terreno por nivel de peligro de aludes en el macizo de Peñalara (sierra de Guadarrama). Mapa compuesto con QGIS [16], usando la topografía del Instituto Geográfico Nacional (IGN).

Las temperaturas del aire y su evolución influyen en el desencadenamiento de aludes de forma compleja. Si las temperaturas son muy bajas en el momento de la nevada y en los momentos posteriores a ésta, la nieve recién caída evolucionará lentamente y el peligro de que se produzca un alud de nieve reciente será más persistente. Además, con temperaturas muy bajas la evolución de la nieve en el manto es hacia un tipo de cristales con menor cohesión entre ellos y con la capa subyacente, y por tanto también se favorece la inestabilidad del manto. $\mathrm{Si}$, al contrario, la temperatura aumenta rápidamente tras la nevada, la nieve reciente tenderá a fundirse y el agua resultante aumentará el peso del manto con lo que se favorecerá el desencadenamiento de aludes de fusión.
El viento y las ventiscas durante la nevada y en los momentos posteriores dan lugar a una redistribución de la nieve reciente, que desaparece de las zonas expuestas al viento y se acumula en las que se encuentran a resguardo de éste. El resultado es una gran variabilidad del espesor del manto y una sobreacumulación de nieve en determinadas áreas. Si, además, estos vientos son persistentes y frecuentes, las zonas de acumulación serán muy a menudo las mismas con lo cual la nieve se concentrará en ellas no sólo en una nevada sino en las sucesivas situaciones que ocurran en la temporada $[6,7]$.

El viento también favorece la aparición de placas de viento en las laderas de sotavento. Estas placas se for- 
man tras la nevada y están débilmente ancladas a la nieve de las capas subyacentes, lo que da lugar a un aumento del peligro de desencadenamiento de aludes de placa $[6,7]$.

Los factores nivológicos tienen tanta o más importancia que los meteorológicos. La evolución del manto estacional y de sus características de humedad, densidad, tipos de cristales, cohesión entre ellos y entre las capas generadas en las sucesivas nevadas, dan lugar a una variación en la estabilidad del manto nivoso. Para conocer las características del manto y su evolución de forma periódica se realizan, en las estaciones nivometeorológicas, estudios detallados del manto que quedan resumidos en los sondeos y perfiles nivometeorológicos.

En resumen, podemos concluir que para realizar una predicción de desencadenamiento de aludes hay que considerar todo un conjunto de factores de índole muy variada, con distintas variabilidades en el tiempo y, además, considerar la evolución del manto nivoso estacional.

La utilización de salidas de sistemas de predicción por conjuntos (SPC) en la predicción de riesgo de aludes se basa, fundamentalmente, en el estudio de variables como la precipitación, las temperaturas, el valor de la altitud de la isocero y la presencia de vientos intensos, así como en la evolución de todas estas variables.

Es importante señalar las limitaciones importantes que presenta el uso de estas salidas en la predicción de cualquier variable en zonas de montaña. En primer lugar, la resolución horizontal de estos modelos presenta una menor calidad que los modelos operativos. En áreas con orografía complicada esta pérdida de resolución se acusa en la calidad de las salidas. En segundo lugar, la orografía del modelo, a pesar de haber ido mejorando progresivamente, todavía presenta importantes diferencias con la orografía real, de forma que estas diferencias pueden ser críticas a la hora de evaluar superación de umbrales de temperatura, acumulación de precipitación en forma de nieve o discriminación de precipitaciones líquidas y sólidas.

A modo de ejemplo se puede observar la Figura 45.2 en la página siguiente, en la que se representa la orografía y la resolución horizontal del SPC del ECMWF,
ECENS (sec. 19.3 en la página 293) en los años 2000 y 2016. Si nos centramos en áreas como el Pirineo aragonés, con numerosos picos que superan los 3000 metros de altitud y valles que se encuentran en torno a 700 - 800 metros, el modelo del año 2000 le asignaba una resolución horizontal de 100 kilómetros y la altitud de la celda de malla que comprende la zona oscilaba entre 600 y 700 metros.

Si consideramos altitudes entre 2200 y 2900 metros, que en el ECENS del 2000 son representadas por 600 ó 700 metros, la estimación de temperaturas puede tener errores entre 10 y $15^{\circ} \mathrm{C}$. Se trata de errores considerables que tendrán impacto tanto en las temperaturas esperadas como en la forma de precipitación prevista, que puede ser en forma de nieve sin que aparezca en el SPC en esta forma, pudiendo reflejarse en forma de agua. De forma que la interpretación de los mapas de uno u otro tipo deberá tener en cuenta estas serias limitaciones.

En contraste, si consideramos modelos más recientes, en concreto el ECENS de 2016, la resolución horizontal y la orografía mejoran de forma notable. La resolución horizontal está en torno a los 18 kilómetros en nuestras latitudes y la orografía sitúa el Pirineo aragonés entre 1500 y 2000 metros de altitud. Estas mejoras provocarían ahora errores de 1 a $9{ }^{\circ} \mathrm{C}$ que, aunque importantes, suponen un aumento considerable en la calidad.

Casos de estudio abordados. Dada la complejidad que entraña el estudio del desencadenamiento de aludes y de la variedad de factores que influyen en él, en el presente trabajo se han seleccionado tres casos de estudio en los que se produjeron aludes de distintas características en áreas de montaña muy variadas de la Península.

En primer lugar, se analiza un alud de nieve reciente que tuvo lugar en la cabecera del río Aguas Limpias en el Pirineo aragonés el día 8 de febrero de 1996. Posteriormente se estudia un alud de placa desencadenado el 2 de marzo de 2014 en el macizo de Peñalara en la sierra de Guadarrama, perteneciente al sistema Central y finalmente nos ocuparemos de varios aludes de placa húmeda desencadenados en la cordillera Cantábrica en torno al 28 de marzo de 2015. 
Orografía - Puntos de Grid - ECENS - Fecha: 01/01/2000

Ciclo: 19r1 Resolución: 120 kms (TL159)

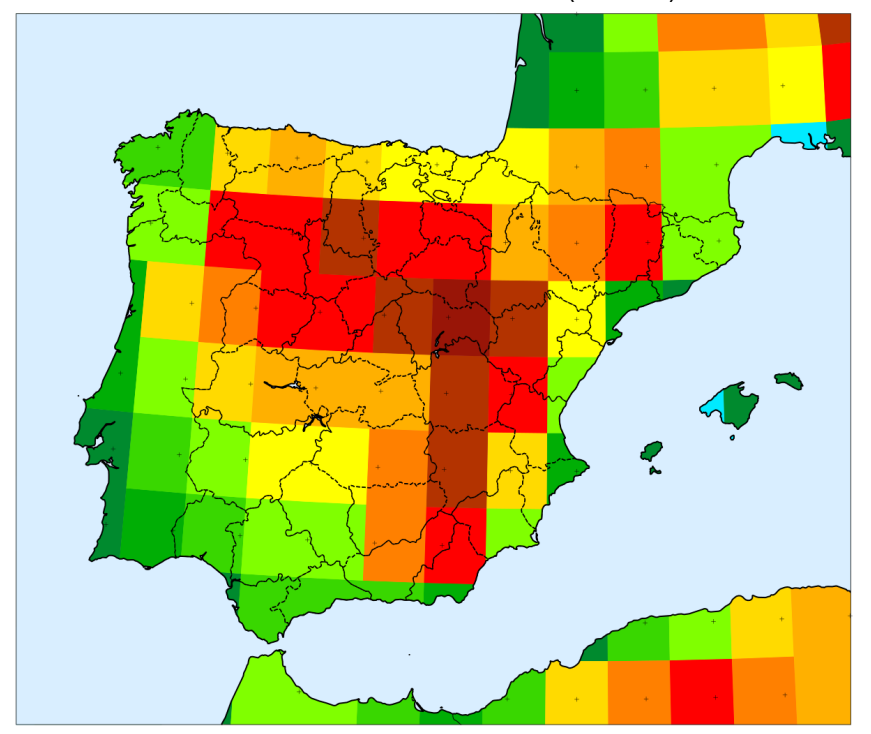

$3000-4000$

2500-3000

$2000-2500$

E 1500-2000

1000-1500

으 $900-1000$

造 $800-900$

ㅇ $700-800$

ह $600-700$

ब) $\square 500-600$

ठ $\square 00-500$

음 $\quad 300-400$

$200-300$

广 $100-200$

$0-100$

$-100-0$

Orografía - Puntos de Grid - ECENS - Fecha: 08/03/2016

Ciclo: 41r2 Resolución: 18 kms (O640)

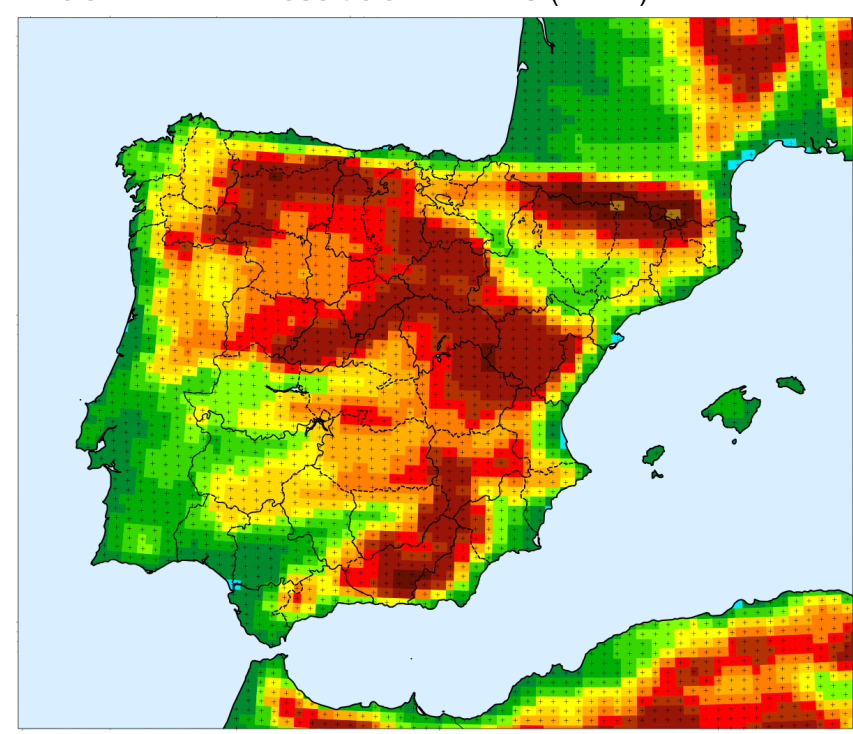

$3000-4000$

2500-3000

2000-2500

E 1500-2000

E $1000-1500$

음 $900-1000$

(1) $800-900$

으 $700-800$

ह $600-700$

$\overline{0} \square 500-600$

400-500

으 $\quad 300-400$

200-300

100-200

0-100

$-100-0$

Figura 45.2: Resolución horizontal y orografía de ECENS en el año 2000, equivalente a 1996 (arriba) y en el año 2016 (abajo). 


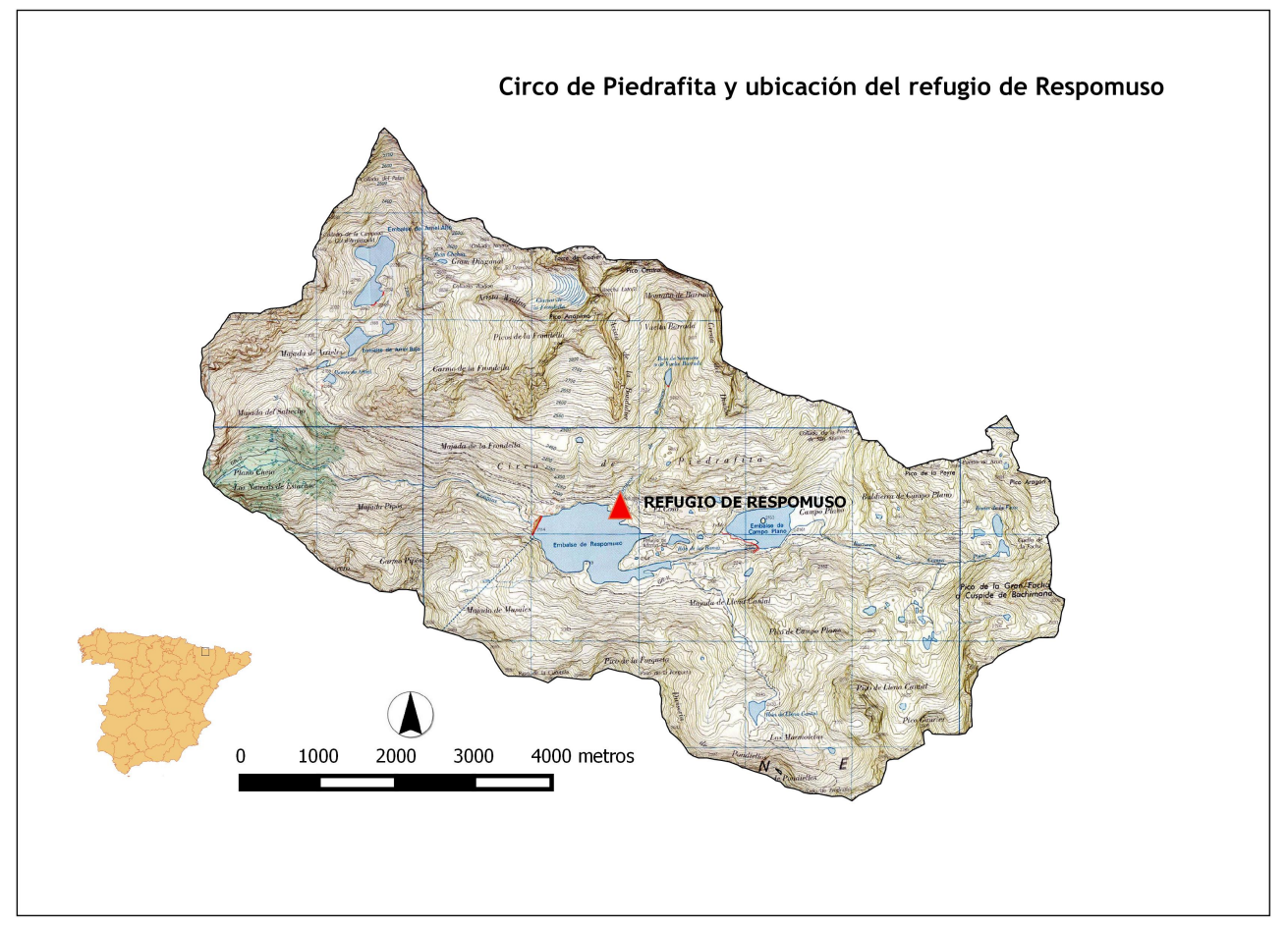

Figura 45.3: Circo de Piedrafita y ubicación del refugio de Respomuso. Mapa compuesto con QGIS [16], usando la topografía del IGN.

\subsection{Caso 1: Alud de nieve recien- te. Circo de Piedrafita, Cabe- cera del río Aguas Limpias. Pi- rineo central aragonés}

\subsection{1 Área de estudio}

El área en el que tuvo lugar el evento de estudio es el circo de Piedrafita, situado en el Pirineo Central Aragonés, al norte de la provincia de Huesca. En concreto el área se encuentra situada en la cabecera del río Aguas Limpias, afluente del Gállego por la izquierda (Figuras 45.3 y 45.4).

Desde el punto de vista litológico y geomorfológico el área de estudio está constituido por materiales paleozoicos afectados por la orogenia hercínica y, posteriormente a ésta, por la intrusión del batolito granítico de Panticosa - Cauterets. En el extremo sur del circo aparecen otros materiales paleozoicos metamórficos correspondientes a la orla metamórfica creada en contacto con el batolito [3].

Sobre estos materiales han actuado procesos de tipo glaciar, periglaciar, nival y fluvial que han dado como resultado un relieve de alta montaña que se caracteriza por sus elevadas altitudes, entre las que destacan picos como el Arriel (2824 m), Frondiellas (3071 m), Balaitus (3146 m), Palas (2970 m), Cambalés (2965 m), Gran Facha (3005 m), Punta Zarra (2947 m), Piedrafita (2969 m), Pondiellos (2893 m), Tebarray (2916 m) y Musales (2654 m), y la existencia de enérgicos relieves y de morfologías como morrenas, rocas aborregadas, canchales, canales de origen mixto nivo-fluvial o valles glaciares colgados como es el caso del propio circo de Piedrafita [15].

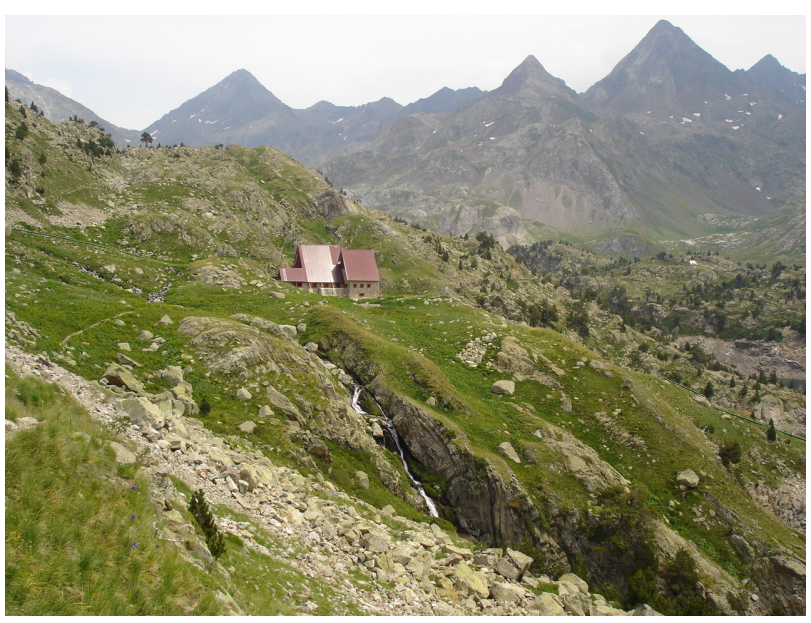

Figura 45.4: Entorno del refugio de Respomuso. 
La vegetación en esta área es escasa y presenta un porte reducido y además se ha visto afectada por una intensa utilización como pastos hasta mediados del siglo $\mathrm{XX}$.

Desde el punto de vista climático el área puede calificarse como un clima de montaña, con bajas temperaturas medias, mínimas bajas, máximas moderadas y amplitud térmica anual considerable. La altitud de la isoterma de $0{ }^{\circ} \mathrm{C}$, factor que condiciona de forma importante los fenómenos de innivación y permanencia de la nieve, presenta una variación anual entre 1611 metros en el mes de febrero y 2998 metros en el mes de octubre [18].

Las precipitaciones y su distribución están condicionadas por la configuración del relieve. La presencia de relieves fuertes y abruptos dificulta la penetración de las masas de aires húmedas del noroeste dando lugar a una disminución de las precipitaciones con respecto a zonas menos protegidas.

El límite lluvia - nieve varía a lo largo del año presentándose las máximas nevadas entre diciembre y marzo.

El manto de nieve cubre el suelo de forma continua todas las temporadas entre los meses de diciembre y mayo.

El espesor de este manto de nieve presenta una gran variabilidad tanto inter como intra anual. En general, el manto no es superior a los dos metros aunque la información procedente de los sondeos nivológicos realizados en la estación nivometeorológica de Respomuso permite asegurar que, puntualmente, este espesor puede alcanzar los cuatro metros.

Las características climatológicas de la zona, con grandes oscilaciones de temperatura, ventiscas y alternancia de momentos secos con otros de precipitaciones importantes, no permiten definir en la evolución del manto periodos únicos de formación y consolidación. Además, el espesor del manto no sólo es sensible a las precipitaciones sino también a los vientos. Así, asociadas a periodos de días con vientos fuertes, el manto de nieve registra importantes modificaciones y oscilaciones en su espesor.

Entre los meses de abril y mayo, cuando las temperaturas comienzan a elevarse, la nieve entra en su periodo de fusión. En este momento el espesor del manto disminuye rápidamente para terminar desapareciendo.

Todos estos factores permiten afirmar que el circo de Piedrafita presenta características geográficas favorables al desencadenamiento de aludes (pendientes, altitudes y litologías favorables, existencia de zonas de acumulación de nieve, vegetación escasa y de porte reducido, precipitaciones abundantes en forma de nieve y persistencia del manto de nieve estacional).

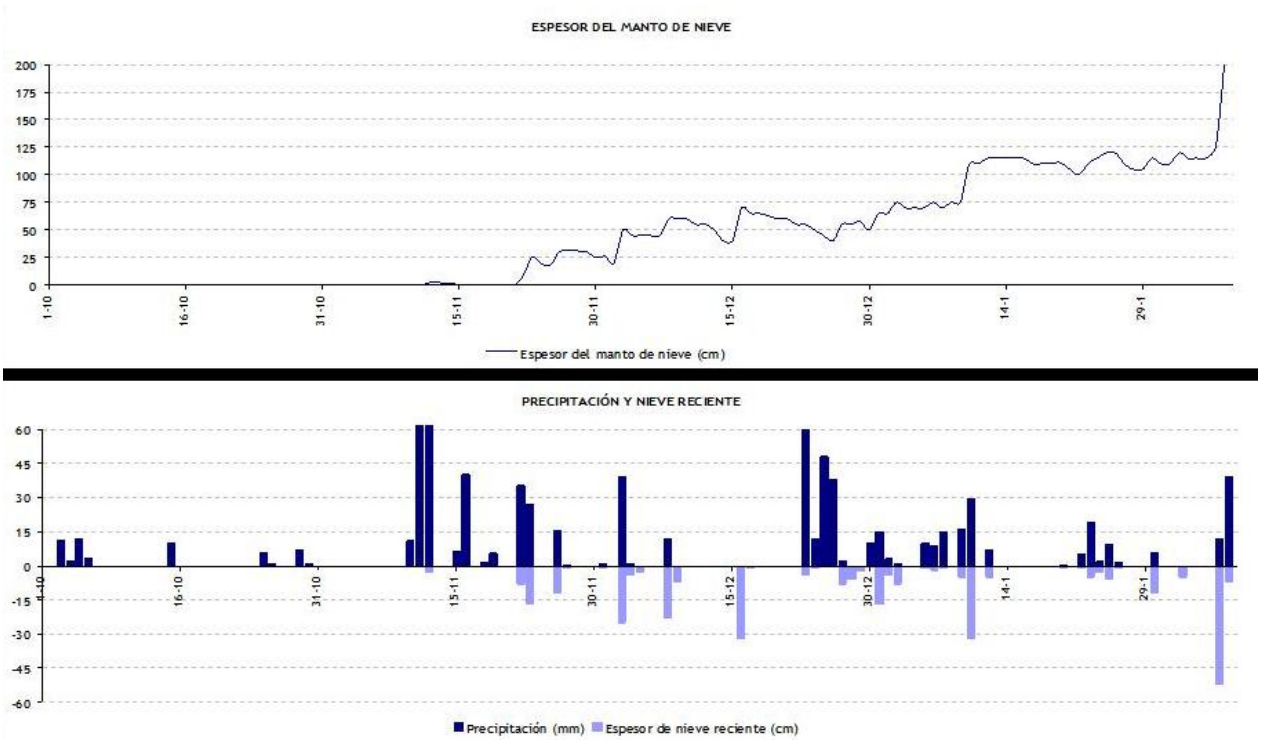

Figura 45.5: Evolución del espesor del manto de nieve y de las precipitaciones registradas durante la temporada 1995 - 1996 en la estación de Respomuso. 

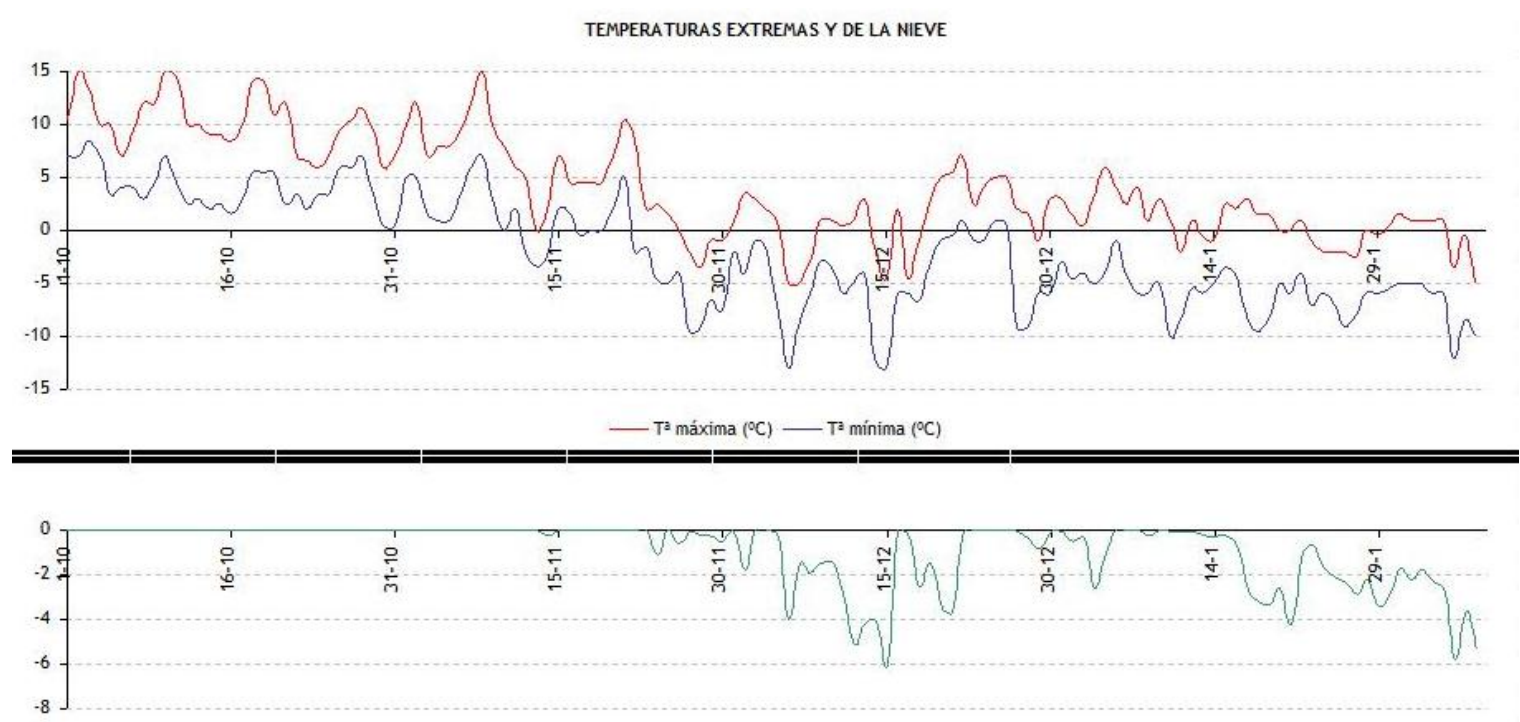

- To de la nieve $\left({ }^{\circ} \mathrm{C}\right)$

Figura 45.6: Evolución de las temperaturas extremas y de la temperatura de la nieve registradas durante la temporada 1995 - 1996 en la estación de Respomuso.

VENTISCA Y ALUDES

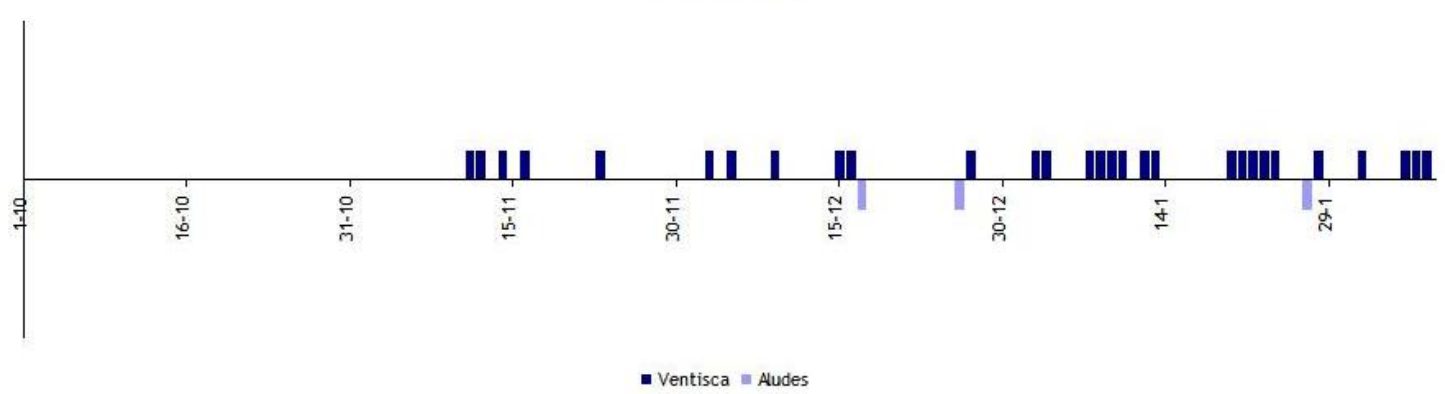

Figura 45.7: Evolución de la ocurrencia de ventiscas y aludes durante la temporada 1995 - 1996 en la estación de Respomuso.

\subsubsection{Descripción del evento}

El invierno de 1995 - 1996 se caracterizó en la cordillera Pirenaica por las importantes nevadas que se produjeron en todas las zonas.

En las estaciones nivometeorológicas del Pirineo aragonés se registraron los espesores de nieve más elevados de todas las temporadas de las que existen observaciones (396 centímetros en el refugio de Góriz, a 2200 metros el día 9 de febrero).

Durante la temporada 1995 - 1996 se registraron en las estaciones nivometeorológicas del Pirineo aragonés alrededor de 150 aludes de distinta magnitud e intensidad.

El día 8 de febrero en el Circo de Piedrafita se registró un alud que alcanzó el refugio de Respomuso.
Factores meteorológicos y nivológicos. La existencia de una estación nivometeorológica en el refugio de Respomuso, atendida por los guardas de éste, permite caracterizar con precisión las condiciones atmosféricas y nivológicas en los días previos a la ocurrencia del alud. Esta estación meteorológica desapareció con el alud.

En la Figura 45.5 en la página anterior aparece la evolución del manto de nieve y las precipitaciones registradas los días anteriores al alud. Como puede observarse, las precipitaciones fueron abundantes los dos días anteriores, siendo, en su mayoría en forma de nieve. Estas precipitaciones provocaron un aumento brusco del espesor del manto de nieve que pasó de menos de 120 centímetros el día 6 de febrero a 200 centímetros el día 8. 
En la Figura 45.6 en la página anterior aparece la evolución de las temperaturas extremas del aire y de la temperatura de la capa superficial de la nieve a lo largo de la temporada 1995 - 1996. Como puede observarse, durante los días inmediatamente anteriores al alud, las temperaturas se mantuvieron por debajo de $0{ }^{\circ} \mathrm{C}$ durante todo el día siendo la temperatura máxima de $-5{ }^{\circ} \mathrm{C}$ el día 7 de febrero. Las bajas temperaturas del aire dieron lugar a que la nieve caída también estuviese a unas temperaturas muy bajas, en torno a $-6^{\circ} \mathrm{C}$ el día 7 , por lo que su evolución fue lenta y hacia la inestabilidad del manto de nieve.

En la Figura 45.7 en la página anterior se representa la ocurrencia de ventiscas y aludes a lo largo de la temporada 1995 - 1996 registradas en el refugio de Respomuso. La observación de la gráfica los días anteriores al desencadenamiento del alud permite apreciar cómo, los días 5, 6 y 7 de febrero se habían registrado ventiscas importantes. La ocurrencia de estas ventiscas nos permite suponer que la nieve reciente y poco cohesionada pudo moverse y acumularse en determinadas zonas favorables para ello dando lugar a un aumento adicional del espesor del manto de nieve.

Las fuertes acumulaciones de nieve que se produjeron los días previos al alud se depositaron sobre un manto de nieve ya consolidado. En los sondeos nivológicos realizados en una estación próxima se observa cómo, entre el 1 y el 9 de febrero, (Figura 45.8) se acumularon más de 60 centímetros y además esta fuerte acumulación de nieve reciente se produjo sobre un manto de nieve ya estabilizado y consolidado de forma que se favorecía el deslizamiento de la capa de nieve superior, más reciente, sobre la inferior por el sobrepeso de la nieve recién caída y la situación desfavorable a la aparición de anclajes que ligaran la nieve recién caída a la de la capa inferior.

En los sondeos se observa también que, entre el 1 y el 9 de febrero, el manto registró un claro enfriamiento, desde un manto prácticamente isotermo el día 1 a uno con un fuerte gradiente vertical de temperatura de la nieve (día 9), hecho que favorece su pérdida de estabilidad.

Los dos sondeos se realizaron en el mismo punto y con condiciones similares (altitud de 1900 metros, ladera de exposición sur y alrededor de las 11 horas).

En resumen, todos los factores meteorológicos y nivológicos observados eran favorables al desencadenamiento de aludes, y unidos a unas condiciones fisiográficas también favorables dieron lugar al desencadenamiento de un alud la madrugada del día 8 de febrero de 1996.

La zona de salida estaba situada en torno a los 2900 metros de altitud en el circo de Frondellas, al noroeste del refugio. La salida del alud fue puntual. La nieve que se puso en movimiento era nieve seca, poco evolucionada y fría. Sólo se deslizó el estrato superior del manto.

La trayectoria del alud estuvo condicionada por su importante fase de aerosol, debida a la poca evolución de la nieve que se puso en movimiento. La fase de aerosol fue también su causa de la gran capacidad destructiva.

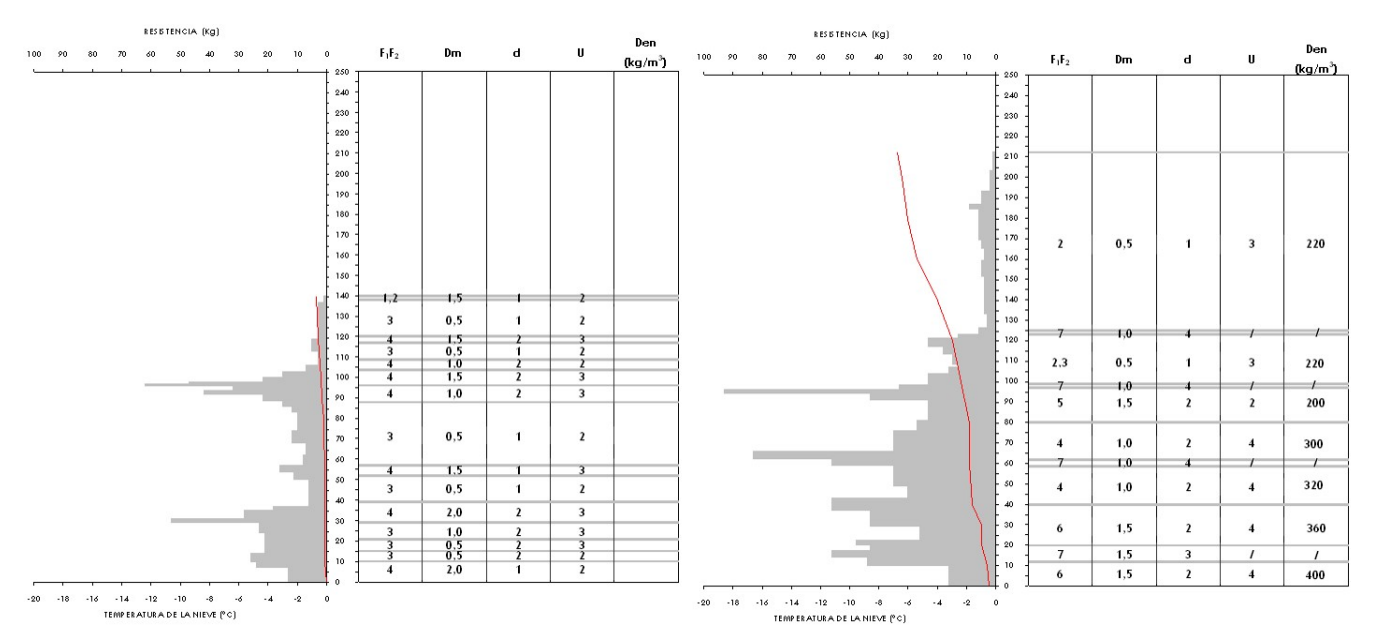

Figura 45.8: Comparación de los sondeos nivológicos de los días anteriores y posteriores al alud, 01-02-1996 (izquierda) y 09-02-1996 (derecha). 


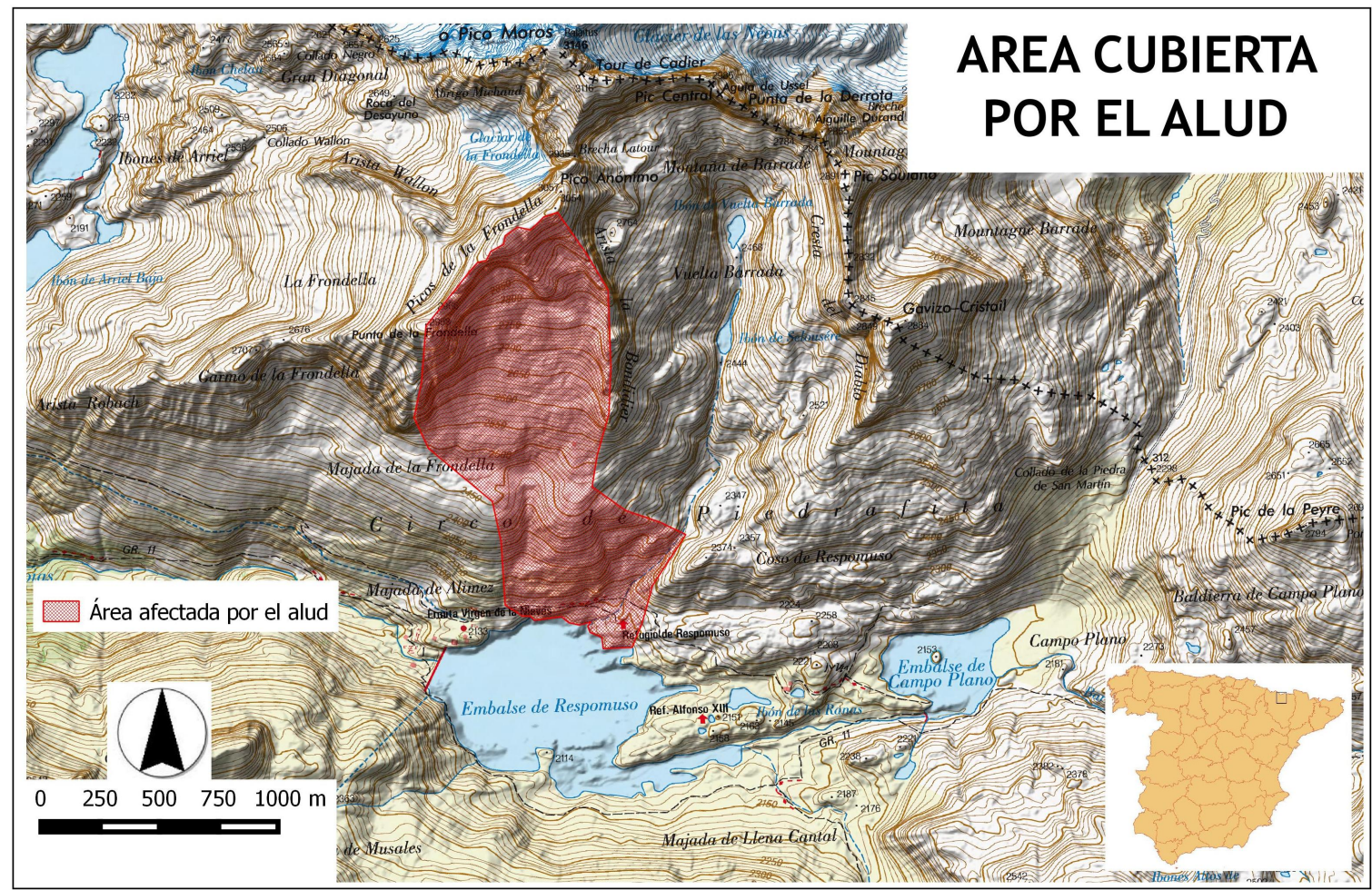

Figura 45.9: Área afectada por el alud. Mapa compuesto con QGIS [16], usando la topografía del IGN.

La zona de depósito alcanzó el embalse de Respomuso. La escasa evolución de la nieve que se movilizó también explica el hecho de que en el depósito no se observaba la presencia de bloques ni bolas de nieve.

El alud alcanzó la fachada norte del refugio de Respomuso (Figura 45.10) provocando importantes daños materiales, valorados en 180000 euros, pero sin daños personales.

El alud tuvo unas características especiales en lo que se refiere a extensión y daños ocasionados. No existe constancia de eventos similares ni en la zona de estudio ni en otras zonas próximas.
Las características meteorológicas y nivológicas de la temporada hacen que no se pueda calificar el alud como un fenómeno extraordinario. De hecho, esa misma semana, existe constancia del desencadenamiento de aludes en numerosos puntos del Pirineo.

La ausencia de una serie de datos nivometeorológicos suficientemente larga impide el cálculo del periodo de retorno del proceso. Sin embargo, algunos estudios realizados con series más largas obtenidas a partir de otras estaciones nivometeorológicas del Pirineo Aragonés de características similares dan una estimación del periodo de retorno de entre uno y tres siglos [2].
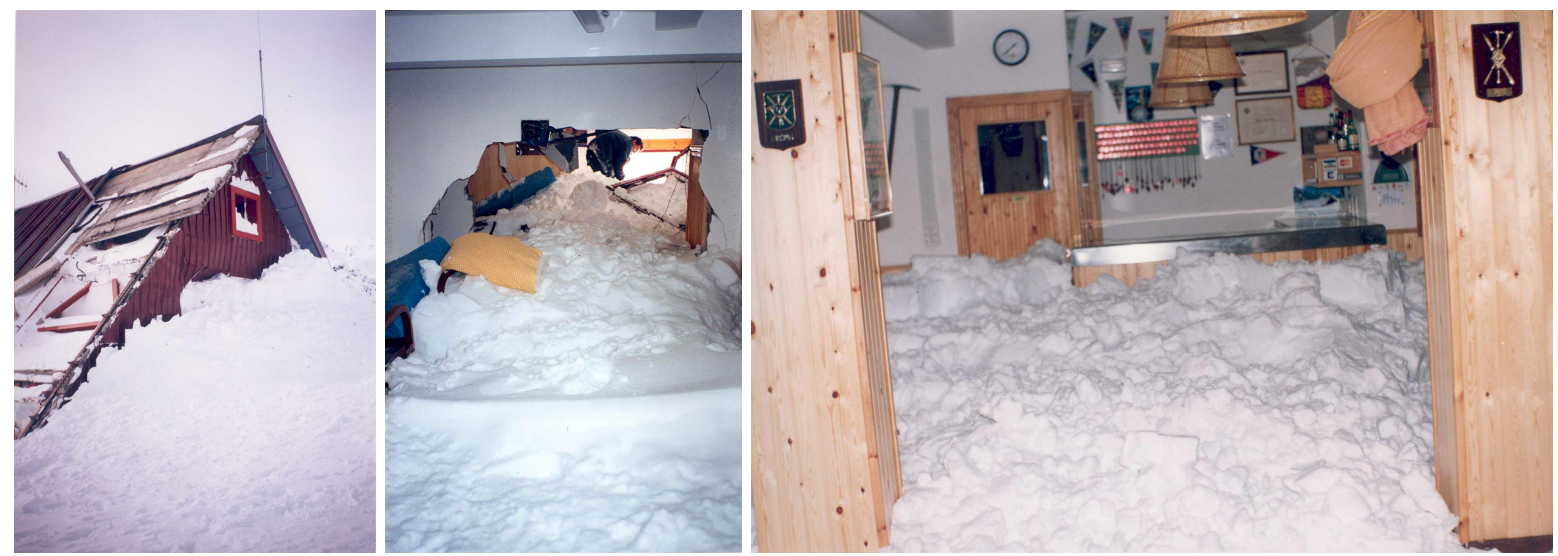

Figura 45.10: Estado de la fachada norte del refugio de Respomuso como consecuencia del alud (izquierda) y estado del interior del refugio de Respomuso como consecuencia del alud (centro y derecha). Fotografías: PRAMES. 


\subsubsection{Predicción del ECENS}

Mapas realizados por ALBERTO FERnÁndEZ MATÍA, ATAP, Agencia Estatal de Meteorología (AEMET).

Incertidumbre y predecibilidad durante el episodio. Cinco días antes del evento, el 3 de febrero de 1996, la pasada del ECENS ofrecía unos escenarios que mostraban relativamente poca incertidumbre para la secuencia de días siguientes (Figura 45.11). Se puede observar cómo, desde el día 4 hasta el día 8 predominaban, en todos los escenarios, flujos de componentes norte y oeste tanto en niveles medios de la troposfera (fila superior de cada panel), como en niveles bajos (fila media), acompañados de precipitación segura (fila inferior). La relativa similitud entre los grupos, al menos en el nordeste peninsular, permite inferir gran predecibilidad atmosférica para estos días en esa zona. Cuatro, tres, dos y un día antes del evento las sucesivas pasadas del ECENS (19960204, 19960205, 19960206, 19960207) ofrecían grupos con incertidumbre similar (no se muestra por brevedad), muy consistentemente con esta pasada de cinco días antes. Una vez transcurrido el evento, se puede decidir que con el uso del modelo determinista de más resolución era suficiente, pero a priori no es tan sencillo tomar esa decisión.
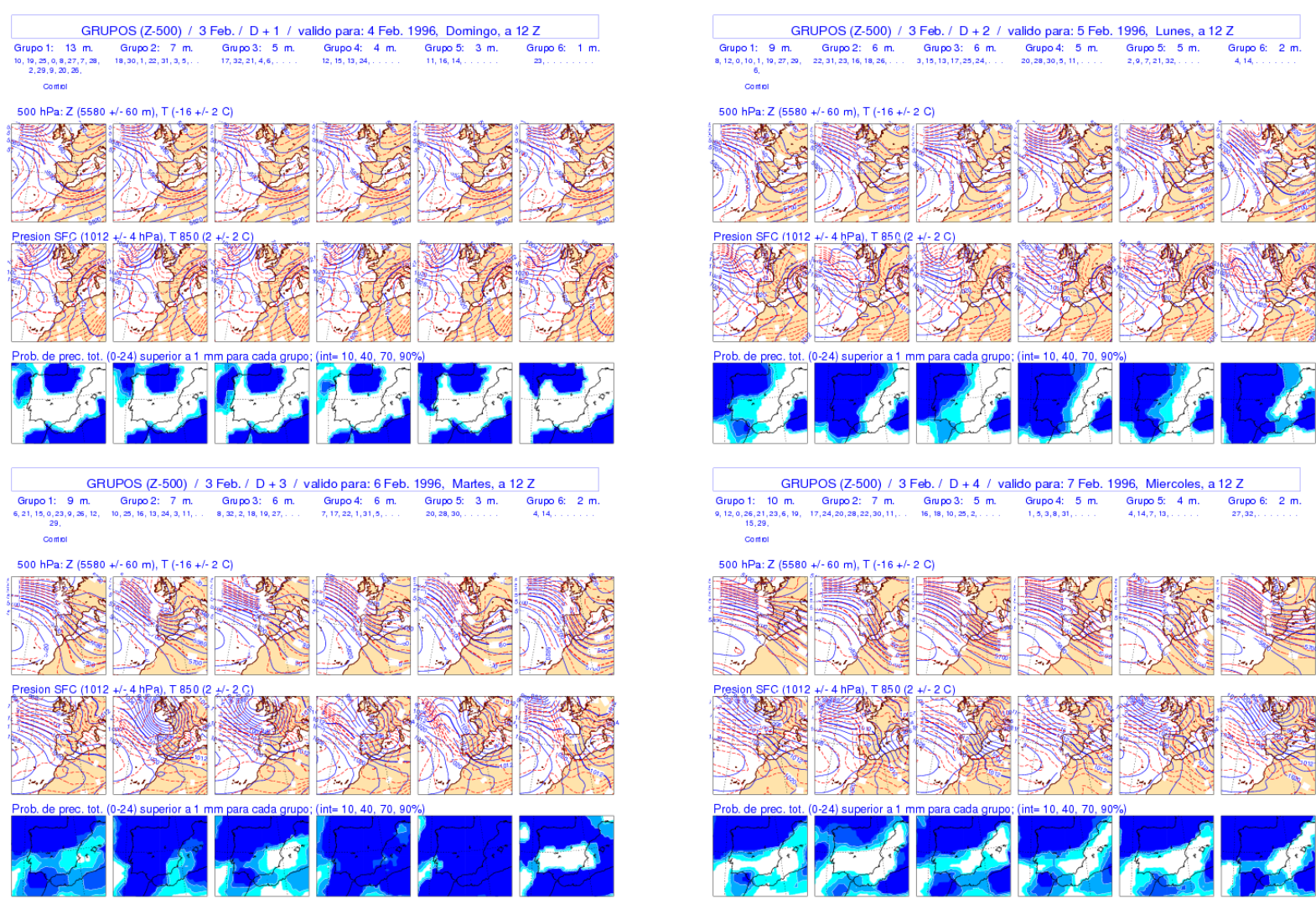

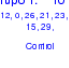

$500 \mathrm{hPa}: \mathrm{Z}(5580+/-60 \mathrm{~m}), \mathrm{T}(-16+/-2 \mathrm{C})$
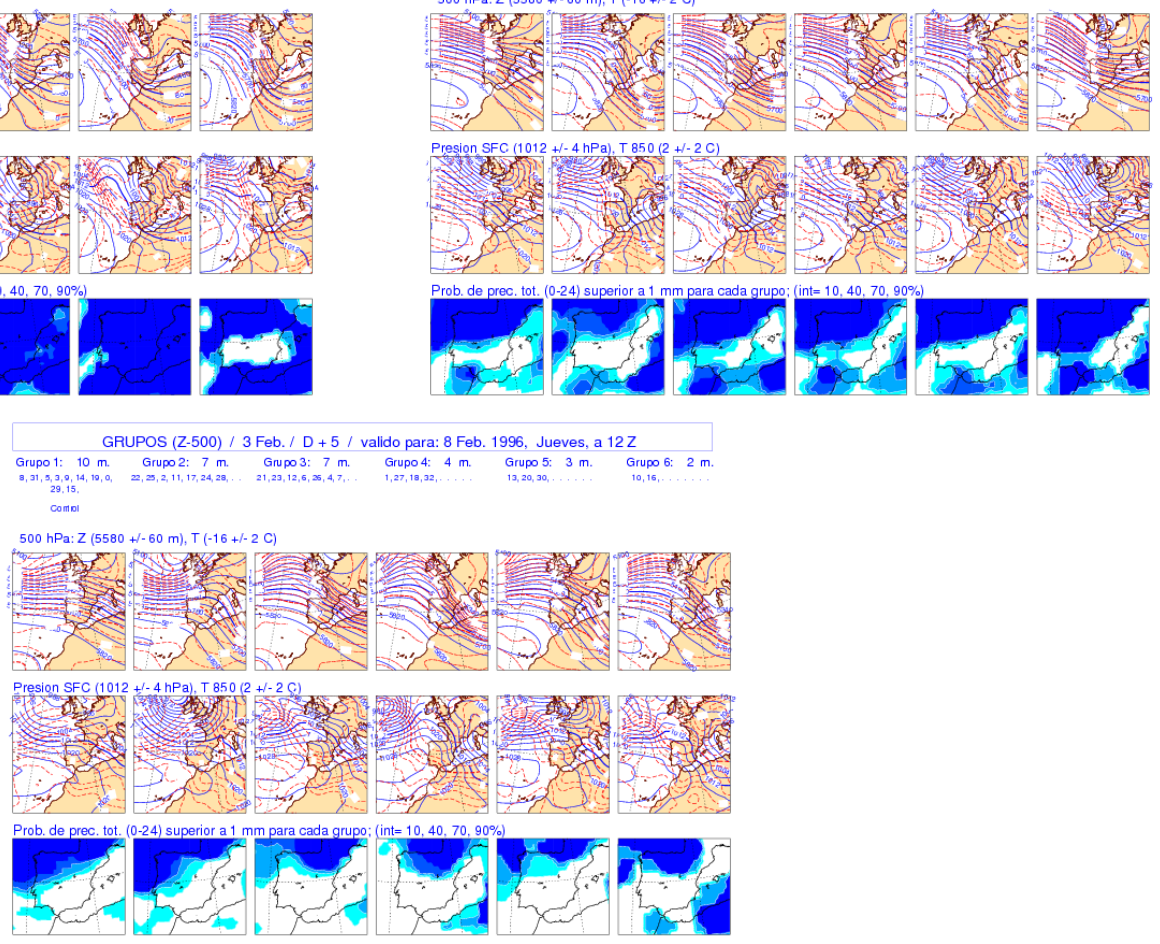

Figura 45.11: Grupos del ECENS del día 3 de febrero de 1996. 

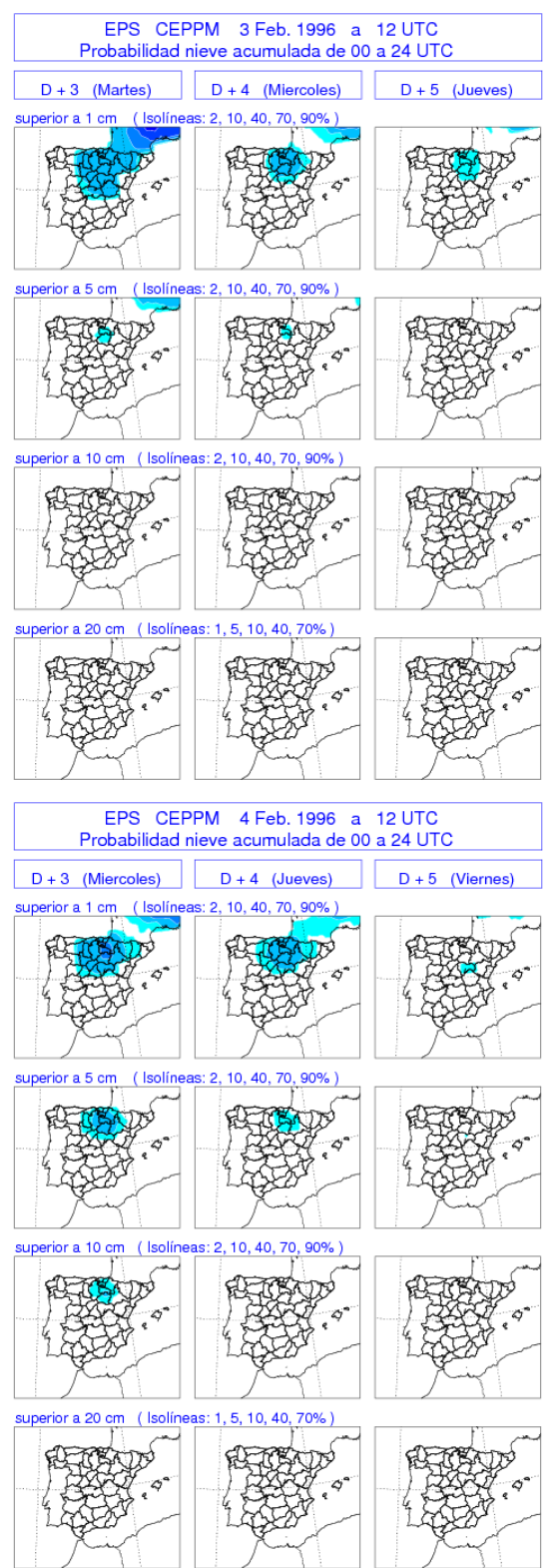
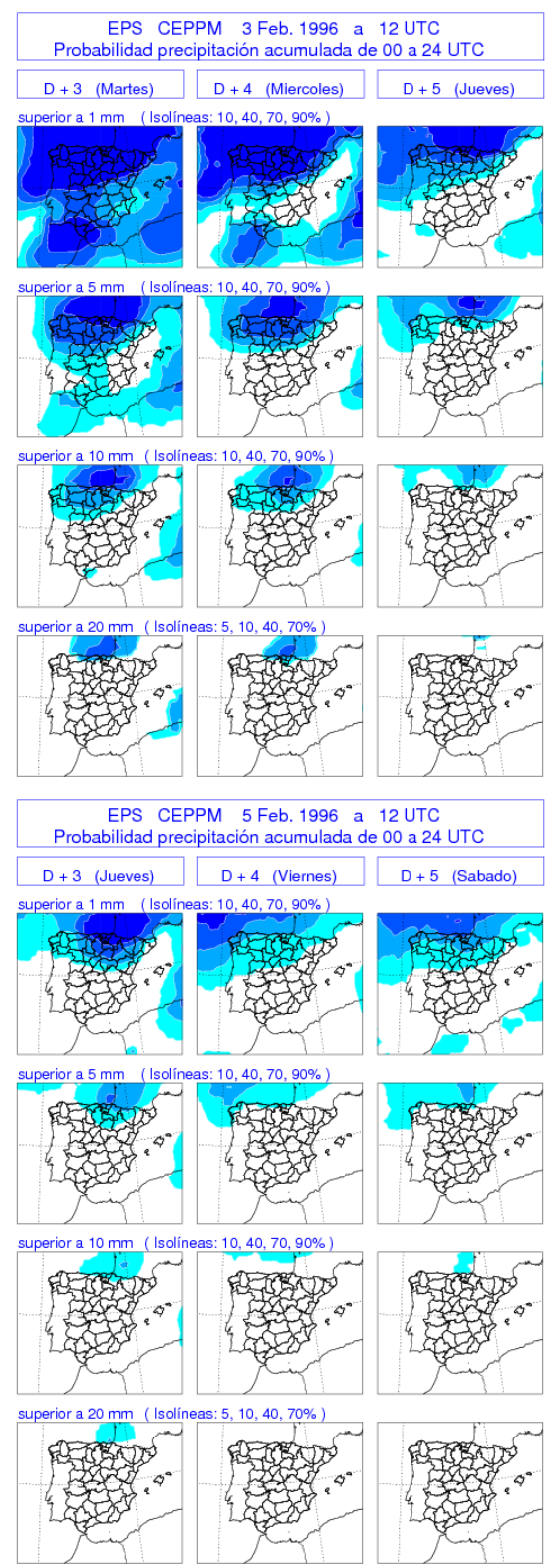

Figura 45.12: Arriba: probabilidades previstas por el ECENS, pasada 19960203, de nieve y precipitación total para los días 6, 7 y 8. Abajo: a la izquierda pasada del ECENS 19960204, nieve y a la derecha pasada 19960205, precipitación total.

Nieve y precipitación total esperadas. En la Figura 45.12, la pasada del día 3 de febrero, cinco días antes del evento, muestra a la izquierda la nieve prevista por el ECENS y a la derecha lo mismo con la precipitación total acumulada, que contiene tanto nieve como agua líquida. Tanto la nieve como la precipitación total (lluvia+nieve) se muestran como mosaicos de diferentes probabilidades de superación de umbrales. Cada columna corresponde a un día (6, 7 y 8). Cada fila corresponde a un umbral diferente. Para la nieve estos umbrales son $1,5,10$ y 20 centímetros y para la precipitación total 1, 5, 10 y 20 milímetros, de modo que, asumiendo que 1 centímetro de nieve equivale normalmente a 1 milímetro de agua, ambas columnas son, hasta cierto punto, equiparables. El martes día 6 podía esperarse nieve por encima de 1 centímetro con probabilidades altas en torno a $40-70 \%$, pero no por encima de 5 centímetros. El miércoles día 7 se quedaba en una probabilidad de $10-40 \%$. Por otro lado, las probabilidades de superar 5 milímetros de precipitación total los días 6 y 7 son altas, alrededor de $70-90 \%$ y 10 milímetros $10-40 \%$. Para el día 8 no se espera nieve, 70-90\% de 1 milímetro de precipitación total y $10-40 \%$ para 5 milímetros.

Aparentemente, poca nieve y cierta cantidad de precipitación total, pero lejos de la acumulación de 80 centímetros medida en la estación. No obstante, dado 
el acentuado sesgo en las altitudes del ensemble, podemos inferir una cantidad de nieve muy superior a la prevista, teniendo como límite tanta cantidad como la precipitación total prevista. Aun teniendo ese sesgo en cuenta, no se pueden esperar las acumulaciones que se dieron. Cuatro días antes del evento, la pasada de 4 de febrero de 1996 aumenta las cantidades esperadas, tanto de nieve (Figura 45.12 en la página anterior, abajo izquierda) como de precipitación total, tanto el día 7 como el día 8 . Tres días antes, la pasada de 5 de febrero de 1996 aumenta notablemente las cantidades de precipitación total (Figura 45.12 en la página anterior, abajo derecha) de modo que, aunque no se alcanzan las acumulaciones que se observaron después, el SPC delimita bien las zonas donde se esperan acumulaciones relativamente altas tanto de nieve, teniendo en cuenta el sesgo, como de precipitación total, en cualquier caso.

Temperaturas esperadas. La Figura 45.13 muestra un mosaico de temperaturas previstas cinco días antes del evento, para los días previos e incluyendo el del alud. En columnas se despliegan los días 4, 5, 6, 7 y 8 , mientras que en filas se despliegan umbrales de temperatura. Cada pequeño mapa representa en colores la probabilidad de que la temperatura sea inferior al umbral especificado. Así, para el día 4 en la zona de interés podemos esperar temperaturas que no excederán los 4 grados y que no serán inferiores a 0 , es decir, de 0 a 4 grados. Se han seleccionado distintas pasadas para los diferentes días, eligiendo los escenarios más fríos previstos para que, aunque se trate de diferentes horizontes de predicción y se pierda consistencia relativa, podemos hacernos una idea de las temperaturas más bajas que pueden esperarse. Puede observarse un enfriamiento muy claro entre los días 4 y 5 en la zona de estudio. A partir del día 6 hay un calentamiento también claro que hace que las probabilidades de tener temperaturas bajo cero en la zona vayan disminuyendo. Para un alud de este tipo, nieve reciente, las condiciones favorables las darían temperaturas muy frías sostenidas durante varios días. Es el caso de los días 4 y 5 , quizá parte del 6, pero no de los días siguientes, aunque sí se perfilan temperaturas inferiores a 8 grados, e incluso inferiores a 4. No obstante, si tenemos en cuenta el sesgo orográfico comentado en apartados anteriores, podemos extrapolar temperaturas bastante inferiores (de 10 a 15 grados de diferencia) a las previstas por el ensemble. De modo que sí que tenemos, en ese caso, seguridad de temperaturas sostenidas por debajo de cero durante el periodo de cinco días.

En consecuencia, de todo lo anterior se concluye que, con la orografía del modelo en el año 2000, no es fácil predecir un evento como el estudiado, que tiene una escala mucho menor que la resolución del modelo tanto en la orografía como en las salidas de las variables meteorológicas. Como mucho se podría haber supuesto una evolución de las variables meteorológicas favorables al desencadenamiento de aludes pero a escala de toda la cordillera Pirenaica.
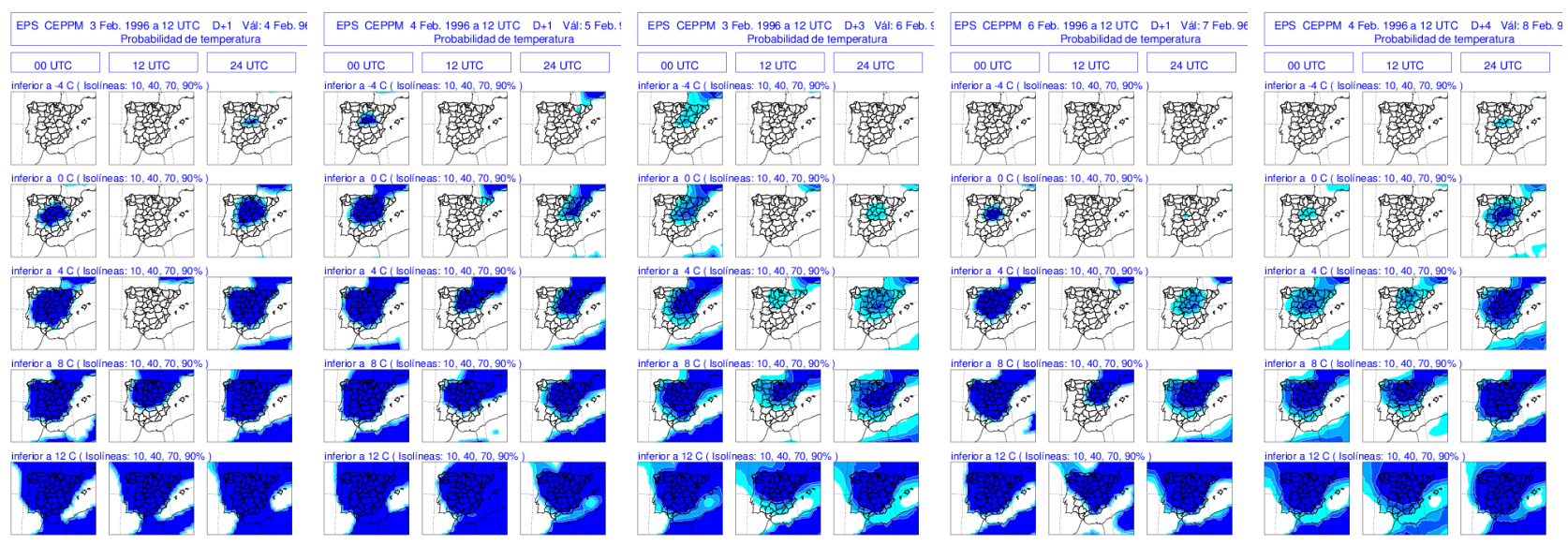

Figura 45.13: Temperaturas previstas días antes por el ECENS, pasada 19960203 para los días 4 y 6 y 19960204 para los días 5 y 8, 19960206 para el día 7, en columnas ordenadas por fecha. 


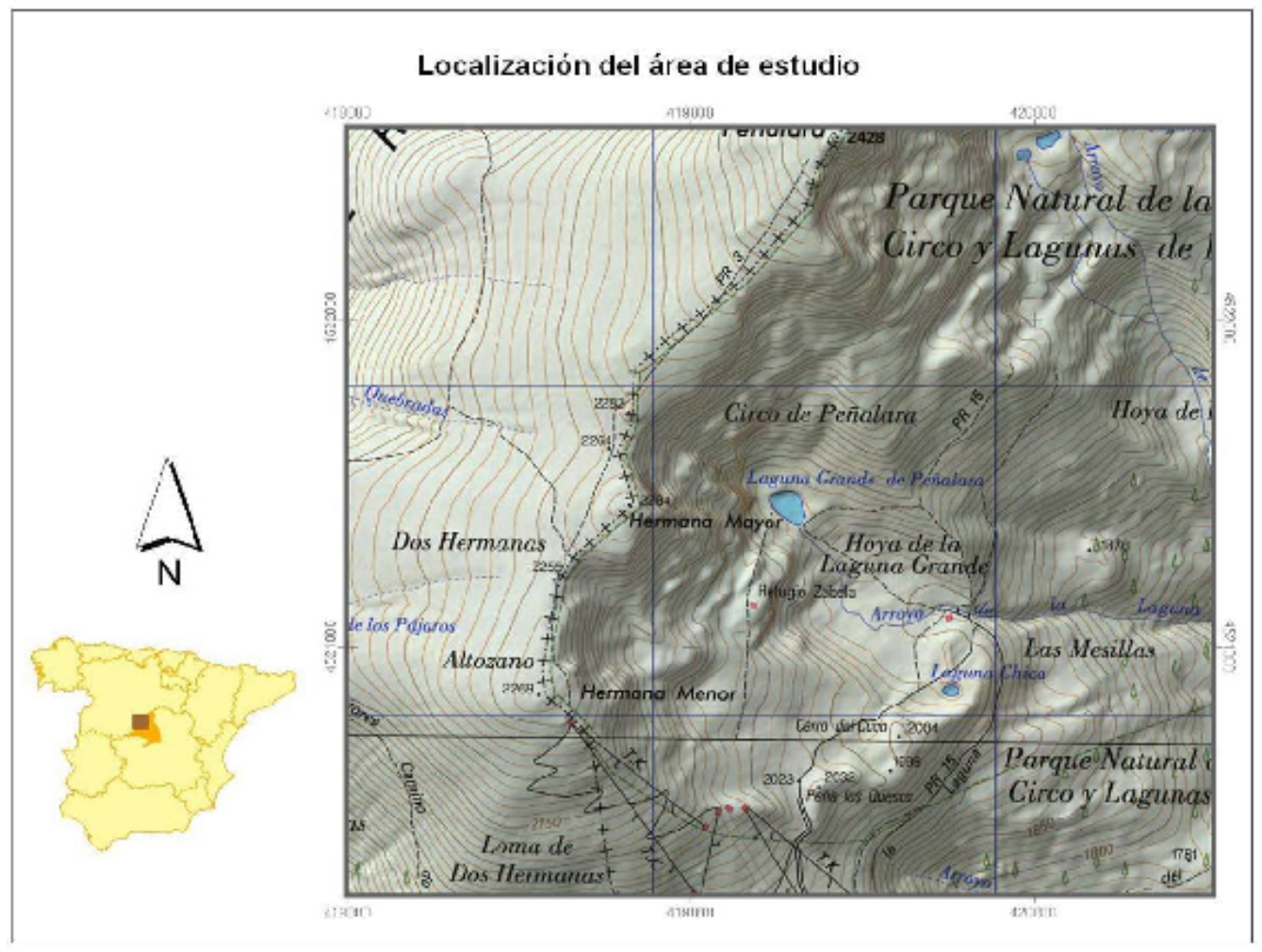

Figura 15: Localización del área de estudio.

Figura 45.14: Localización del área de estudio de Peñalara. Mapa compuesto con SAGA [4], usando la topografía del IGN.

\subsection{Caso 2: Alud de placa. Maci- zo de Peñalara, sierra de Gua- darrama, sistema Central}

\subsection{1 Área de estudio}

El Macizo de Peñalara se encuentra en el entorno de las cumbres más elevadas de la sierra de Guadarrama que forma parte, a su vez, del sistema Central. El Macizo está constituido por materiales gneisecos, básicamente gneises glandulares, con intrusiones graníticas. Sobre estos materiales han actuado distintos procesos periglaciares, glaciares y fluviales.

En épocas preglaciares, las pulsaciones térmicas frías y secas provocaron la formación de campos de bloques por procesos de macrogelifracción de la roca (Sanz, 1986), la aparición de un manto de alteración de materiales finos, la formación de permafrost en las vertientes menos expuestas a la radiación solar [11] y la reordenación de los bloques en el manto de alteración formando conjuntos de lenguas y lóbulos [5] que perduran en la actualidad sobre todo en las vertientes occidentales del macizo.
La instalación de los glaciares tuvo lugar entre 21000 a 23000 años antes de la actualidad [12]. Los glaciares más activos se encontraban en las laderas con orientación este, protegidos de los vientos dominantes y de la máxima radiación solar, y las laderas occidentales se caracterizaban por la escasa acumulación de nieve y hielo. La asimetría en la distribución de los glaciares tuvo importantes consecuencias geomorfológicas. En las vertientes orientales, además de provocar la aparición de morfologías como morrenas, circos y depresiones, los glaciares barrieron el manto de alteración previo eliminándolo en muchas áreas y reduciéndolo considerablemente en otras. En las laderas orientadas al oeste la presencia glaciar fue menos importante, por lo que el manto de alteración permanece inalterado en la mayor parte de estos sectores.

A partir de la retirada de los glaciares (entre $19000 \mathrm{y}$ 16000 años antes de la actualidad) el relieve de la zona ha registrado pocas variaciones. La desaparición de hielo estuvo acompañada por una actividad periglaciar intensa. La nieve ha sido otro de los agentes clave en el modelado actual del terreno, aportando agua al suelo, suavizando la influencia de los cambios de temperatura del aire en la temperatura del suelo, condicionando 
la distribución de procesos geomorfológicos como la acción torrencial, el lavado de materiales finos, el movimiento de bloques, la solifluxión, la gelifracción y la formación de movimientos en masa y, en ámbitos de montaña mediterránea, aislando el suelo de las lluvias primaverales, limitando el desarrollo de la vegetación al periodo estival y exponiendo el suelo poco estabilizado a la erosión causada por las lluvias otoñales [11].

La acción fluvial también ha originado variaciones en el relieve. Los torrentes se han instalado en las laderas incidiendo sus cauces en el manto de alteración y en los materiales de las morrenas y mostrando en algunos puntos un incipiente proceso de jerarquización [11].

El resultado de esta evolución hace que una de las características principales del Macizo de Peñalara en la actualidad sea su marcada asimetría este - oeste en su aspecto geomorfológico, que se refleja en otras facetas como la distribución y persistencia del manto de nieve o en las relacionadas con la distribución de la vegetación, ya que son todos ellos factores interrelacionados.

Las áreas preglaciares ocupan las laderas occidentales del Macizo (poco afectadas por la acción glaciar) y los sectores de las laderas orientales por debajo de los a 1800 metros, que corresponde a la altitud mínima que alcanzaron los glaciares.

Los relieves glaciares aparecen básicamente en los sectores del Macizo situados en las vertientes orientales de éste que superan los 1800 metros de altitud. Se pueden distinguir dos circos, el de Dos Hermanas al sur y el de la Laguna al norte, y un conjunto de morrenas que cierran estos circos y que presentan una dirección marcada del noroeste al sureste. En la parte inferior de los circos y entre los cordones morrénicos aparecen áreas de turberas [13].

Las áreas glaciadas y las no glaciadas conectan en el área de cumbres, en las que se encuentran los picos Peñalara (2428 m), Dos Hermanas (2284 y 2269 m) y Claveles $(2387 \mathrm{~m})$. En el área de cumbres aparecen depresiones de origen nival con profundidades variables pero que, en general, no superan el metro de profundidad y de unos metros de diámetro, cuyo fondo está cubierto por un manto de alteración en el que aparecen incrustados bloques de dimensiones decimétricas [11].

Los agentes más importantes de modelado en la actualidad son una moderada acción periglaciar, los movi- mientos en masa que se desarrollan en ambas laderas, la acción torrencial y los procesos ligados a la presencia de la nieve.

El clima del área de estudio se puede encuadrar dentro del clima mediterráneo de montaña. Entre las características principales de este clima están las suaves temperaturas invernales, las altas temperaturas y la elevada aridez estival y la acusada variabilidad tanto espacial como temporal (inter e intra anual) de los parámetros meteorológicos. Esta variabilidad se aprecia sobre todo en la precipitación y la acumulación de la nieve, que no se distribuyen espacialmente siguiendo patrones altitudinales, sino que están condicionados por el régimen de vientos dominantes y por la orografía, de forma que las mayores acumulaciones de nieve se localizan en las vertientes orientales del macizo, a sotavento de los vientos dominantes y en zonas con una topografía favorable, heredada de la época glaciar.

La variación temporal de la temperatura, la precipitación, la intensidad del viento o el espesor del manto de nieve también presentan fuertes contrastes dentro de un año concreto y entre unos años a otros. Así hay años en los que se superan los 2000 milímetros de precipitación (1972), mientras que otros no se alcanzan los 1000 milímetros (1990). Además de esta variabilidad interanual de las variables climatológicas, otro de los rasgos que caracterizan al clima de estas áreas es el hecho frecuente de que se produzcan rápidas oscilaciones, de forma que, en el plazo de pocos días, se pueden registrar cambios en la temperatura de más de $10{ }^{\circ} \mathrm{C}$ o precipitaciones diarias que superan los valores medios para ese mes.

\subsubsection{Descripción del evento}

El 2 de marzo de 2014 se produjo un alud de placa de nieve húmeda. El desencadenamiento fue precedido de copiosas nevadas y precipitaciones en forma de agua que llegaron a acumular 178 milímetros en 24 horas en la estación del Puerto de Cotos.

Los días previos al alud el manto de nieve estuvo presente de forma continua desde los 1500 metros de altitud, con unos 50 centímetros a 1800 metros y en torno a los 150 centímetros a $2100 \mathrm{~m}$, y con acumulaciones que superaban los 300 centímetros en circos y canales. El manto antiguo se encontraba bien estabilizado. Encima de los estratos antiguos, las precipitaciones más recientes acumularon un espesor de entre 30 y 50 centímetros más bien de forma uniforme, aunque el viento predominante del noroeste provocó 
más cantidad en orientaciones sur, observándose en estas laderas estructuras de placa por la presencia de una capa de nieve granulada poco profunda bajo una capa superficial más cohesionada. Las precipitaciones líquidas del día previo al alud dieron lugar a importantes aumentos en la humedad del manto y a su inestabilización.
En las Figuras 45.15 y 45.16 se representan respectivamente la evolución de las temperaturas extremas, las precipitaciones acumuladas en 24 horas y los meteoros registrados entre los días 22 de febrero y 2 de marzo de 2014 en la estación meteorológica del Puerto de Cotos.
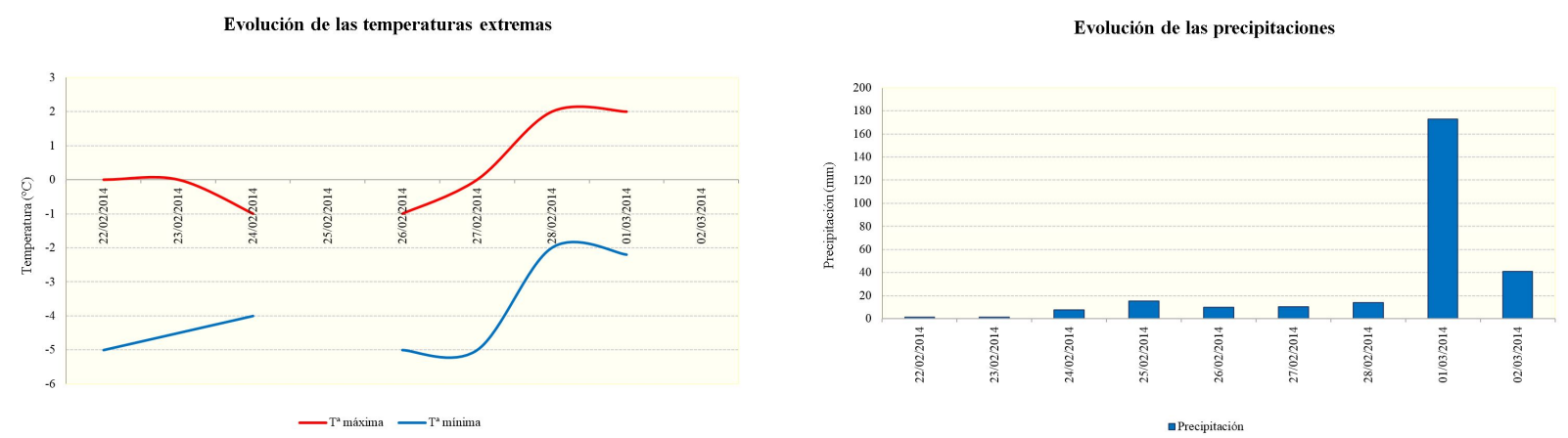

Figura 45.15: Evolución de las temperaturas extremas (izquierda) y de las precipitaciones (derecha).

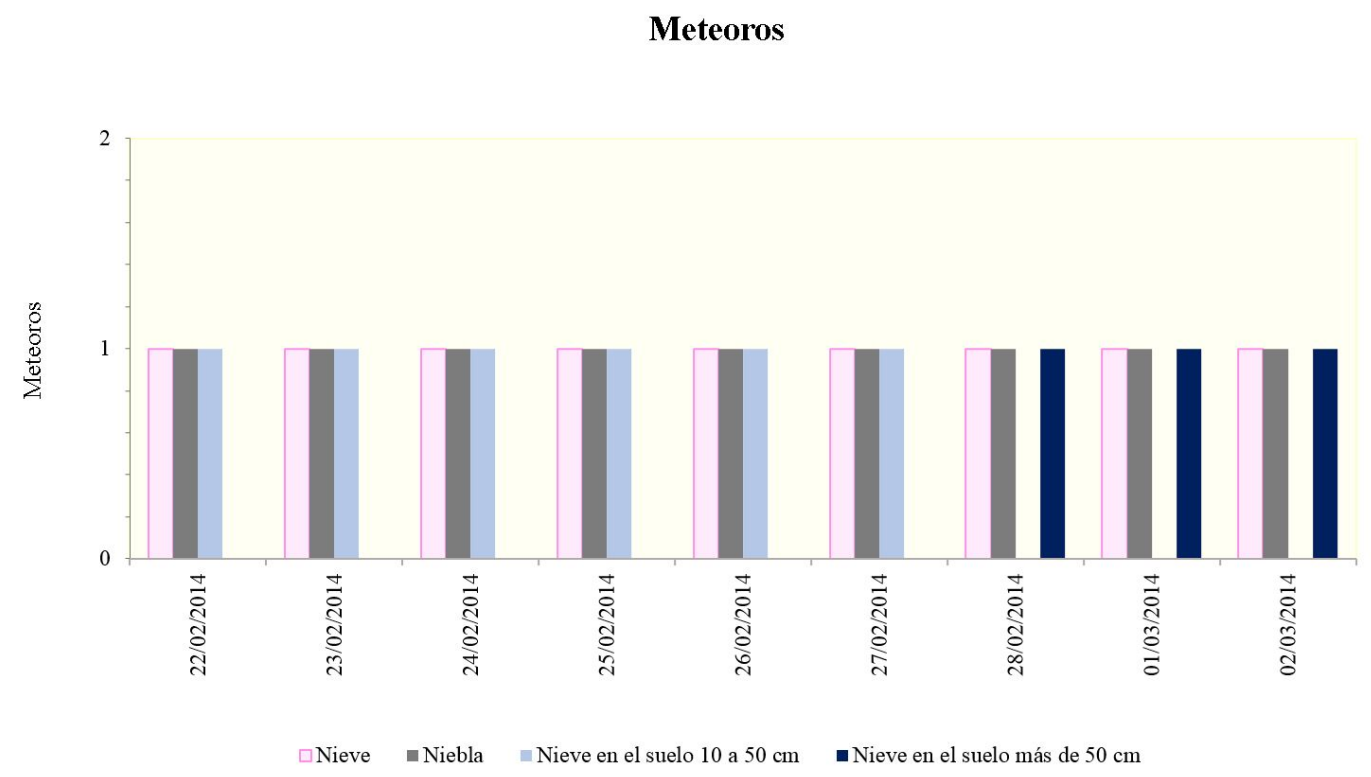

Figura 45.16: Evolución de los meteoros.

Como puede observarse, las temperaturas fueron muy bajas los días anteriores al alud, ascendiendo a partir del día 28 de febrero de forma ligera. Sin embargo, el factor verdaderamente determinante para el desencadenamiento del alud fueron las intensas precipitaciones en forma de nieve que se produjeron el día 1 de marzo como se observa en la Figura 45.15 derecha. Ese día se acumularon más de 170 milímetros de precipitación en forma de nieve en la estación. El manto de nieve existente previamente se vio sometido a un sobrepeso importante, tanto por la nieve como por la precipitación líquida caída a lo largo del día 1 de marzo.

El alud se desencadenó en la vertiente oriental del macizo, con un labio de corte de casi 1 kilómetro de ancho, hasta 100 metros de profundidad y que deslizó más de 300 metros de desnivel hasta la Laguna Grande arrancando a su paso algunas instalaciones del Parque Nacional. 


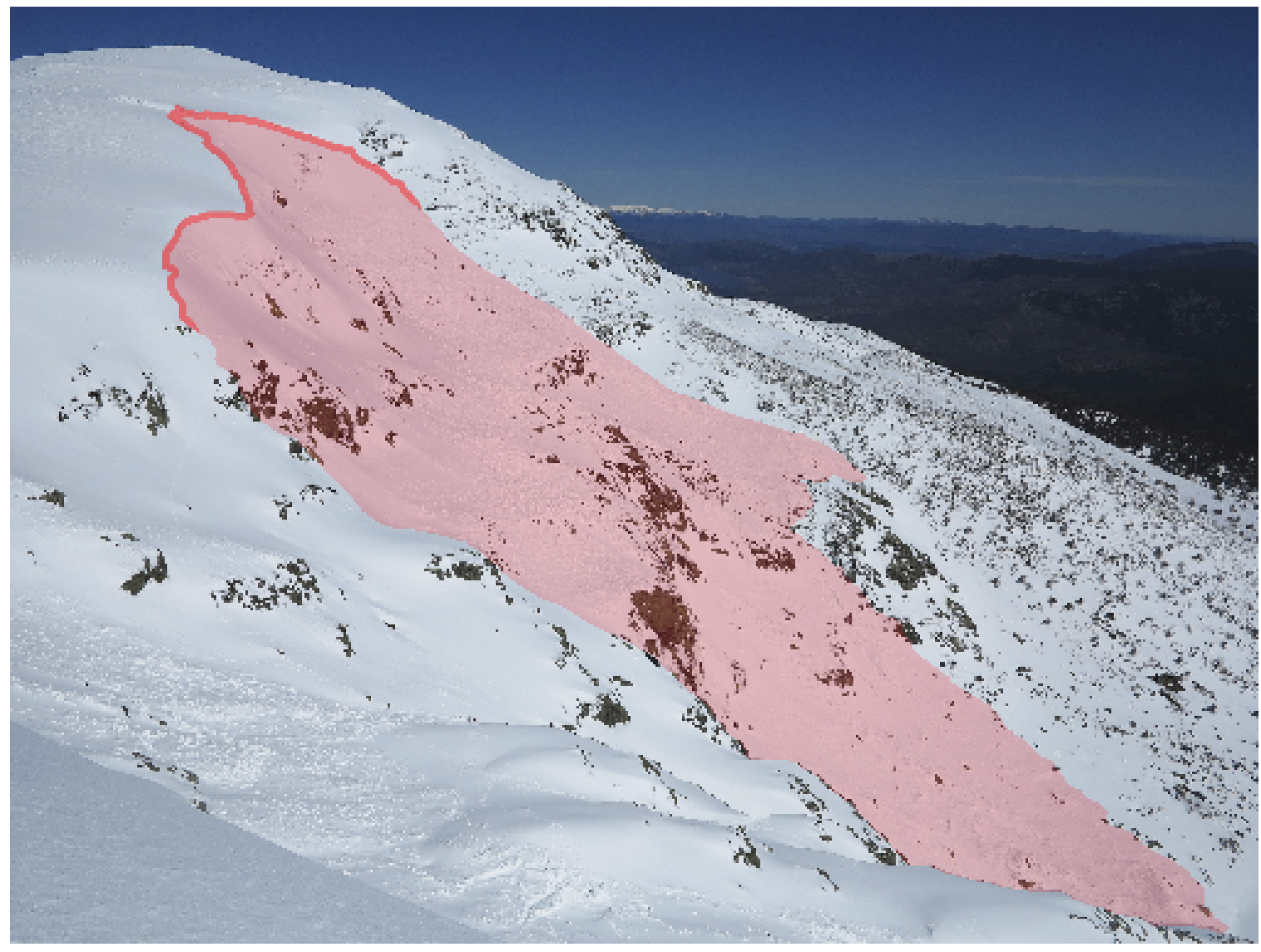

Figura 45.17: Área afectada por el alud. LUIS PANTOJA, Observatorio de Navacerrada, AEMET.

\subsubsection{Predicción del ECENS}

Incertidumbre y predecibilidad durante el episodio. Cinco días antes del evento, el 26 de febrero de 2014, la pasada del ECENS ofrecía unos escenarios que mostraban relativamente algo más de incertidumbre para la secuencia de días siguientes que el caso de 1996 (no se muestra por brevedad). A más incertidumbre, mayor es el valor añadido del ECENS con respecto al ECHRES y, aunque su resolución y orografía sean más pobres, permite una predicción más fiable en general.

Nieve y precipitación total esperadas. En la Figura 45.18 en la página siguiente se muestra, para la pasada del día 26 de febrero de 2014, cinco días antes del evento, la nieve prevista por el ECENS (arriba) y la precipitación total acumulada (abajo), lluvia+nieve, que contiene tanto nieve como agua líquida. Tanto la nieve como la precipitación total se muestran como mosaicos de distintos días por probabilidades de superación de diferentes umbrales. Cada columna corresponde a un día previsto $(26,27,28,1$ y 2$)$ y cada fila corresponde a un umbral diferente. Para la nieve estos umbrales son $1,2,5,10$ y 20 centímetros y para la precipitación total $1,2,5,10$ y 20 milímetros de agua equivalente, de modo que, asumiendo que 1 centímetro de nieve equivale aproximadamente a 1 milímetro de agua, ambas columnas son, hasta cierto punto, equiparables.

Puede apreciarse que ECENS predice cantidades de nieve y precipitación total significativamente altas el día 1 . El valor acumulado observado de $170 \mathrm{~cm}$ de nieve no puede esperarse de forma realista de un modelo o un SPC. Sin embargo, llama la atención que, incluso para umbrales altos $(10,20 \mathrm{~mm})$, hay señal de probabilidad aunque sea baja. Considerando nuestra experiencia en el uso de SPC, estas señales son llamadas de atención sobre un posible fenómeno adverso.

Un día antes del evento, la pasada de 1 de marzo de 2014 aumenta las cantidades esperadas, tanto de nieve como de precipitación total (no mostrado por brevedad), aunque asumimos que un día antes ya puede usarse con razonable fiabilidad el ECHRES. En cualquier caso, aunque con más días de antelación no se alcanzan las acumulaciones que se observaron después, el ECENS delimita bien las zonas donde se esperan acumulaciones relativamente altas. 

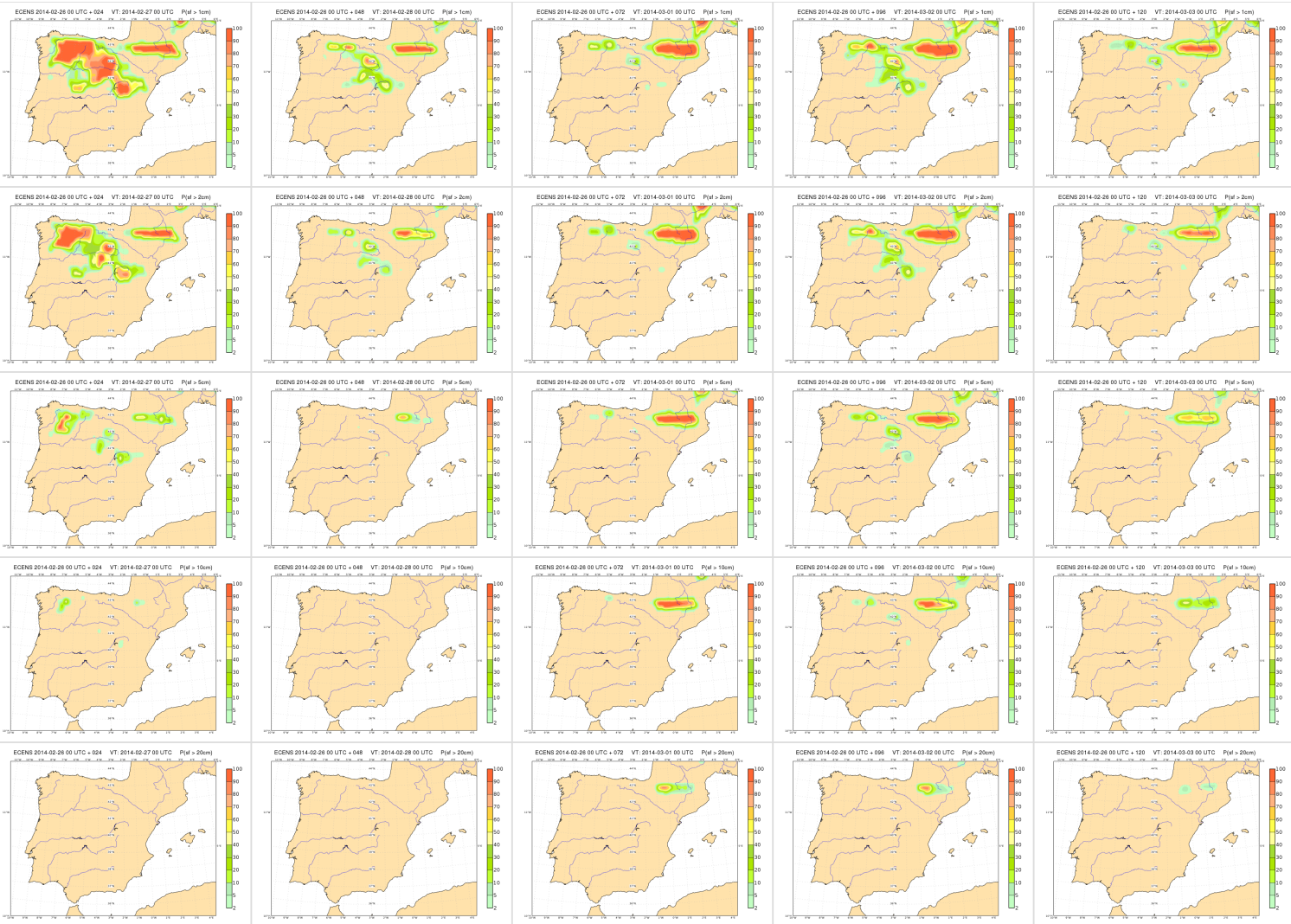

Figura 45.18: Arriba: probabilidades de nieve (00-24 UTC) estimadas por el ECENS pasada 2014022600 para el abanico de días 26-02-2014 a 02-03-2014. Las columnas representan los días 26, 27, 28, 01 y 02 y las filas los umbrales 1, 2, 5, 10, $20 \mathrm{~cm}$ de nieve. Abajo: como arriba, aquí precipitación total, con umbrales de acumulación 1, $2,5,10,20 \mathrm{~mm}$.
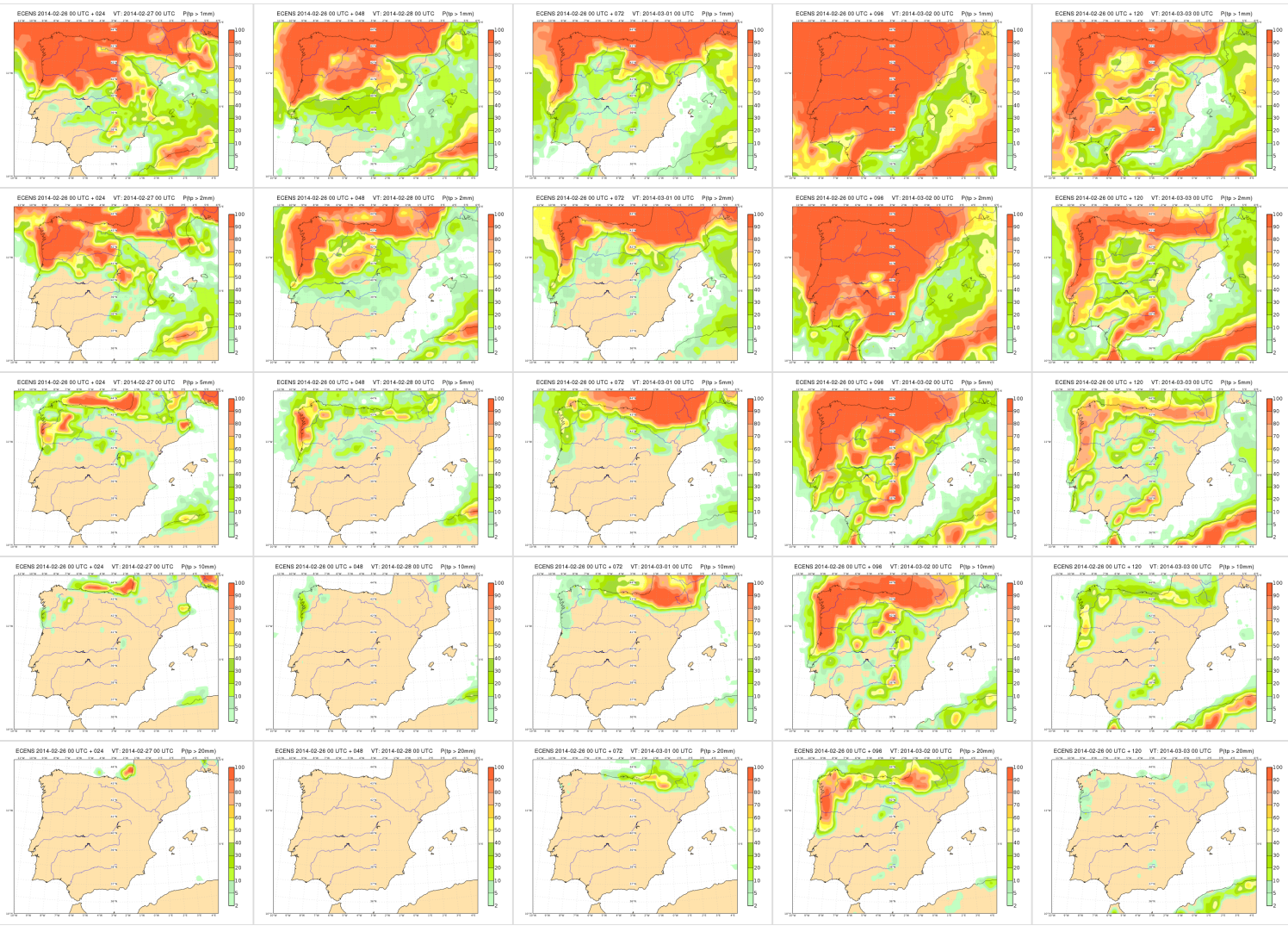

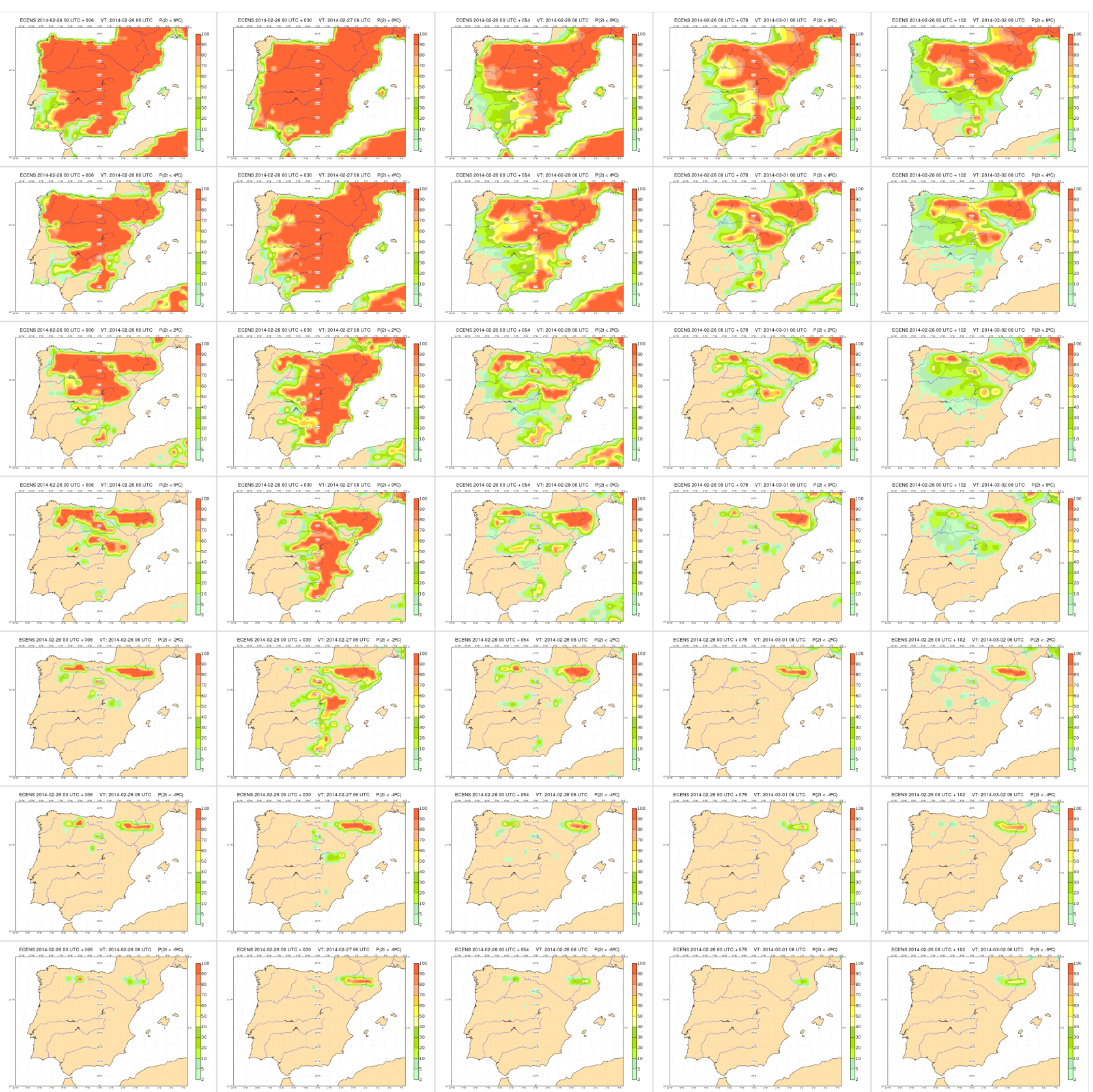

Figura 45.19: Temperaturas mínimas previstas cinco días días antes por el ECENS, pasada 2014022600 para el abanico de días 27-02-2014 a 02-03-2014. Las columnas representan los días 26, 27, 28, 01 y 02 y las filas representan los umbrales $6,4,2,0,-2,-4$ y $-6{ }^{\circ} \mathrm{C}$ (ver texto).

Temperaturas esperadas. La Figura 45.19 muestra un mosaico de temperaturas mínimas previstas por ECENS, pasada 2014022600, cinco días antes del evento, para los días previos e incluyendo el del alud, es decir 27-02-2014 a 02-03-2014. Las columnas representan por tanto los días $26,27,28,01$ y 02 y las filas representan los umbrales $6,4,2,0,-2,-4$ y $-6{ }^{\circ} \mathrm{C}$. Se trata de temperaturas a las 06 UTC, que asumimos como suficientemente cercanas al valor mínimo diario. Como decíamos en el primer caso de alud, cada pequeño mapa representa en colores la probabilidad de que la temperatura sea inferior al umbral especificado.
De este modo, para la sierra de Guadarrama podemos esperar temperaturas bajo cero los 2-3 primeros días y después un calentamiento gradual. Las diferencias, como mínimo, en orografía y resolución entre el ECENS de 1996 y el del año 2014 son claras: la predicción de aludes en 1996 resultaba muy dificultosa y requería extrapolar mucha información por la falta de precisión en las altitudes del modelo, mientras que en 2014 las pautas y tendencias térmicas, así como pluviométricas, siguen con nitidez los patrones orográficos.

En resumen, con las salidas del ECENS del día 26 de febrero de 2014 se puede «intuir» que las precipita- 
ciones serían de nieve los días 26,27 y 28 de febrero $\mathrm{y}$, abundantes y en forma de lluvia, los días 1 y 2 de marzo. Además, se observa una subida rápida de las temperaturas entre los días 27 y 1 . La combinación de nieve reciente, ascenso de temperaturas y aumento de agua en el manto debido la lluvia aumenta la inestabilidad del manto de nieve y nos podría haber puesto sobre aviso de un escenario favorable al desencadenamiento de aludes en el sistema Central. 


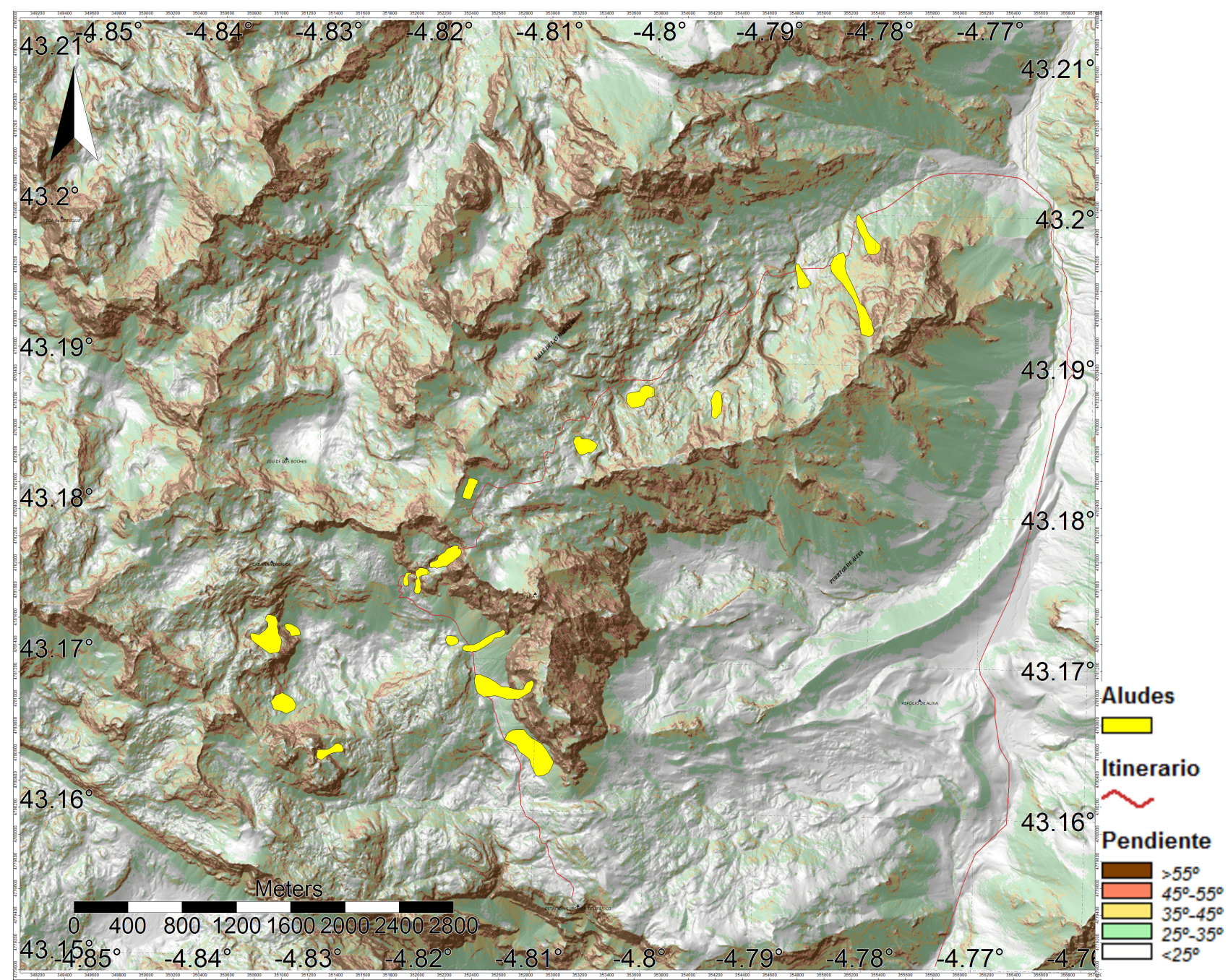

Figura 45.20: Mapa de pendientes, en grados, del área recorrida. Aludes en amarillo e itinerario en rojo. Compuesto con SAGA [4], usando la topografía del IGN

\subsection{Caso 3: Alud de placa hú- meda. Grupo de cumbres de Peña Vieja. Picos de Europa. 28/03/2015}

\subsection{1 Área de estudio}

Los Picos de Europa constituyen un conjunto montañoso de características particulares. Están situados al norte del sector central de la cordillera Cantábrica, separados de ella por cuencas intramontanas como el valle de Liébana, o por profundos desfiladeros como el del río Sella, al oeste.

El conjunto está dividido en tres macizos individualizados por estrechos tajos fluviales, y la roca sobre la que están edificados es casi exclusivamente caliza, altamente soluble. Esta circunstancia impide la construcción de una red hidrológica superficial en el interior de los macizos, y el agua que cae se pierde rápidamente en el subsuelo. El paisaje está dominado por altas torres y profundos hoyos, jous en el habla local, y presenta todo el amplio repertorio de formas superficiales propias de los paisajes cársticos (Figura 45.20). Otro rasgo destacado de estas montañas es su elevada pluviometría, y la acusada disimetría que alcanza la precipitación en una u otra vertiente del macizo. En la fachada marítima, la precipitación supera los 1.800 milímetros anuales a 900 metros de altitud, y distintas aproximaciones y observaciones indican que en la franja comprendida entre 1500 y 2000 metros de altitud, la precipitación recibida estaría en torno a 2500 milímetros. Sin embargo, a sotavento de los vientos marítimos, la precipitación no supera los 1200 milímetros a 1100 metros de altitud. 


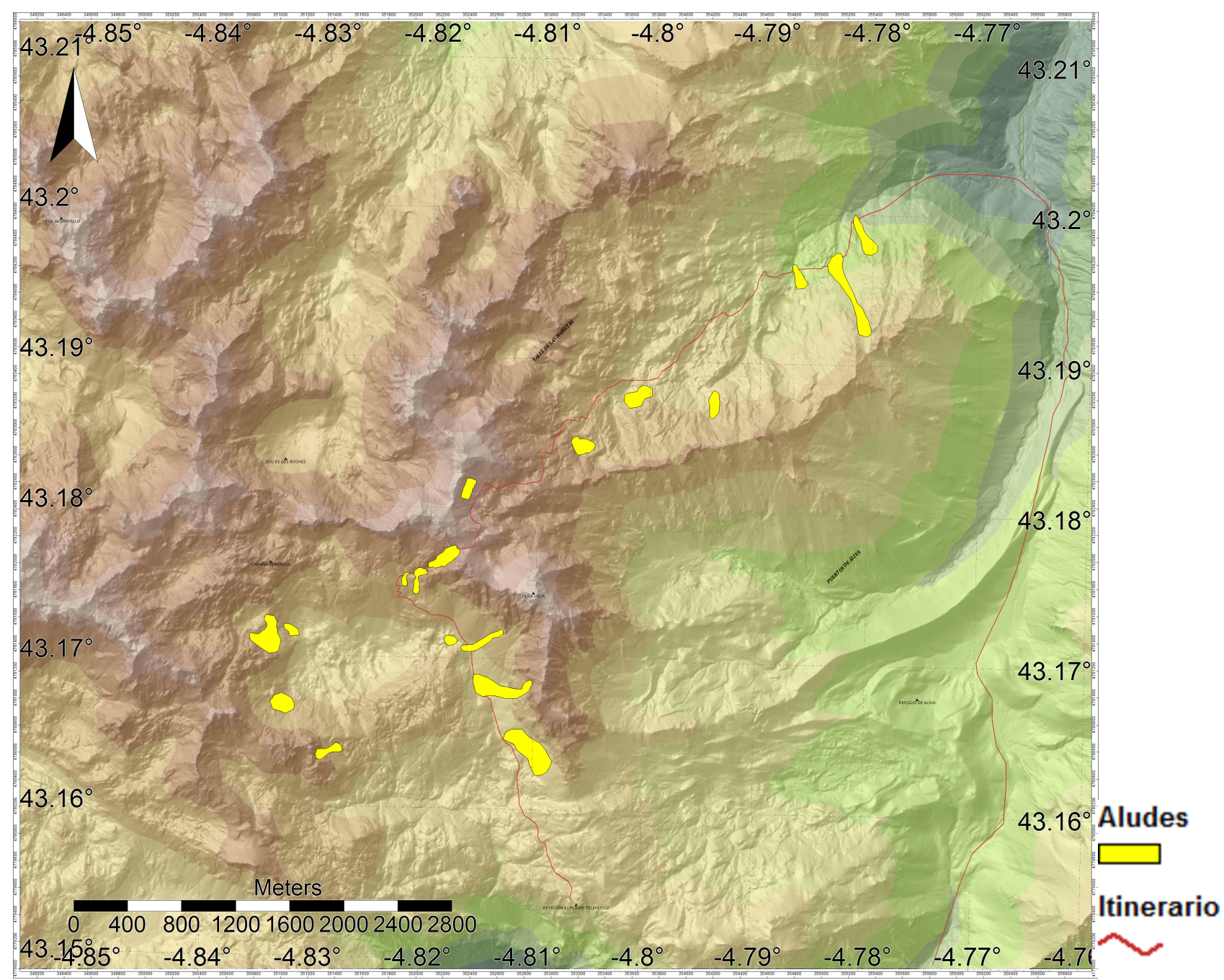

Figura 45.21: Sector de Peña Vieja, Valle de las Moñetas y vegas de Áliva en el macizo central de los Picos de Europa. La línea roja corresponde al itinerario realizado el 28 de marzo y los recintos amarillos a los aludes observados aquel día. Base cartográfica del Mapa Topográfico Nacional E:1/25 000 editado por el Instituto Geográfico Nacional.

Aunque la altitud es moderada, pues la zona de cumbres se desarrolla entre 2000 y $2600 \mathrm{~m}$, las fuertes pendientes, lo escarpado del terreno, la falta de agua en superficie y el predominio del roquedo desnudo otorgan a estas montañas las características de lo que se da en llamar la alta montaña.

La observación de aludes se realizó el 28 de marzo de 2015, a lo largo de un itinerario bien conocido por los esquiadores de montaña, en torno al grupo de cumbres de Peña Vieja. Desde Fuente Dé se atraviesan los Lagos de Lloroza, $1850 \mathrm{~m}$ y se alcanza el Collado de la Canalona, $2450 \mathrm{~m}$, para descender después por el Valle de Las Moñetas hasta las Vegas de Sotres $(1100 \mathrm{~m})$, y cerrar el circuito atravesando los Puertos de Áliva (1450 m) hasta alcanzar el camino que desciende finalmente a Espinama (950 m).
(Figura 45.21).

\subsubsection{Descripción del evento}

El invierno de 2015 había sido extraordinario por la abundante precipitación caída, y el episodio de nevadas del mes de febrero acumuló, en promedio, dos metros de nieve a 2000 metros de altitud. Las temperaturas se mantuvieron bajas, con la isoterma de $0{ }^{\circ} \mathrm{C}$ por debajo de los 2000 metros (Figura 45.22 en la página siguiente). El mes de marzo empezó con un repunte de las temperaturas que duró hasta mediados de mes, e hizo ascender la isoterma de $0{ }^{\circ} \mathrm{C}$ por encima de 3000 metros. Sin embargo, entre los días 15 a 26 volvió a caer y se mantuvo por debajo de $1500 \mathrm{~m}$, para subir por encima de 2500 a partir del día 26. 


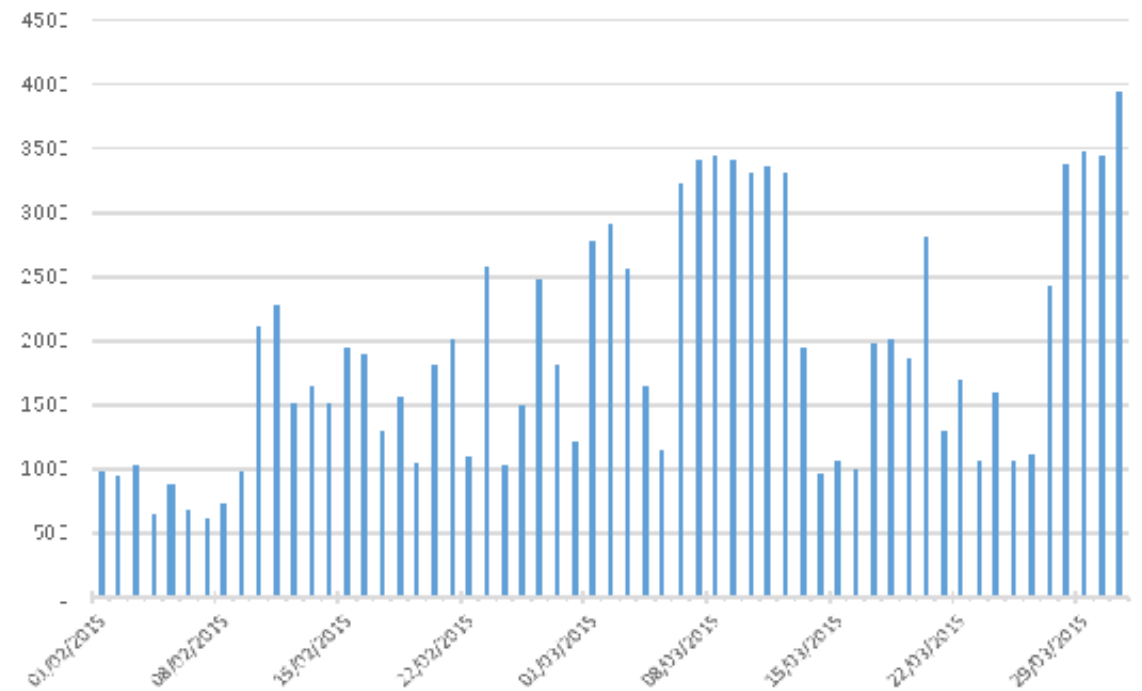

Figura 45.22: Altura de la isoterma de $0^{\circ} \mathrm{C}$, en metros, entre el 1 de febrero y el 31 de marzo de 2015.

En la víspera de esta subida acusada y rápida, nevó de forma generalizada, acumulándose el día 25 un manto de nieve de 10 centímetros de espesor a 1000 metros de altitud, de 15 centímetros a 1300 metros, y de entre 25 y 50 centímetros en las zonas más altas del macizo, en cotas comprendidas entre 1800 y 2500 metros.

El día 26, el nivel de la isocero subió de 1100 metros a medianoche, hasta 2600 metros al mediodía. La llegada del frente cálido convirtió la precipitación de nieve en lluvia, y entre las 7 de la mañana del día 26 y las 7 de la mañana del día 27 se recogieron en torno a 50 milímetros de lluvia. El agua caída dibujó sobre la superficie nevada profundos canales que conducían el agua por la superficie de la nieve (Figura 45.23).

Pero a la vez, donde el manto era suficientemente poroso, o a través de las grietas que se forman en el contacto de la roca con la nieve, la lluvia fue penetrando el manto y humedeciéndolo, hasta alcanzar la superficie donde se asentaba la última nevada de los días 24 y 25 , un estrato de entre 20 y 50 centímetros que constituiría la placa propensa a desprenderse.
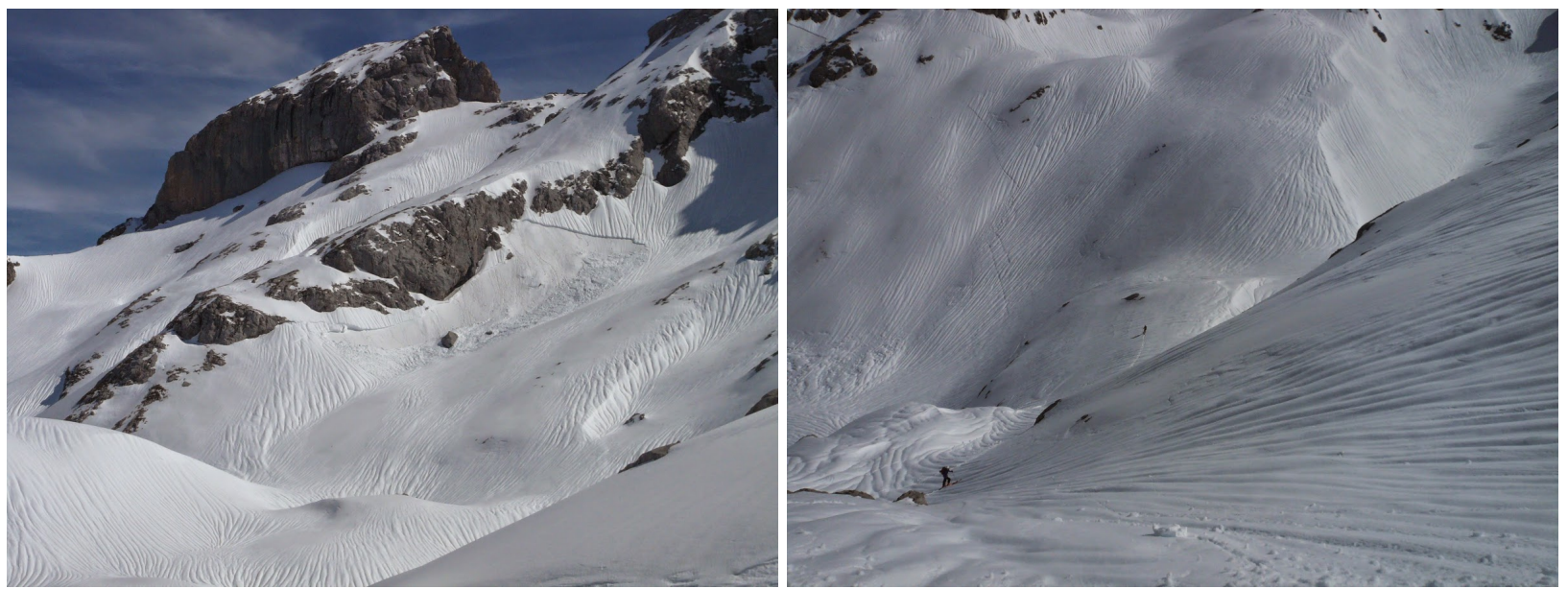

Figura 45.23: Canales de escorrentía sobre el manto nival, y alud de placa húmeda desprendido bajo los Cuetos de Juan de la Cuadra, 2237 m (izquierda). Canales de escorrentía sobre el manto nival, bajando al lago de las Moñetas, $1750 \mathrm{~m}$ (derecha).

\subsubsection{Características de los aludes obser- vados}

El tipo de aludes observado corresponde en todos los casos a los denominados de placa húmeda. Se llaman 
así porque en el manto se reconoce una estructura de placa que se sobrecarga al recoger humedad de la lluvia caída, o por efecto de la fusión. Frecuentemente, la lluvia caída penetra el manto -percola- y produce el efecto de lubricar la base de la placa, aumentando la discontinuidad y facilitando su deslizamiento.

Durante el recorrido se ha anotado la presencia de diecinueve aludes de placa húmeda. Como era de esperar, a la vista de las condiciones que desencadenaron el episodio, se han encontrado en laderas de todas las orientaciones, sin mostrar preferencias por ninguna. El espesor de la placa desprendida es variable, dependiendo del emplazamiento y la altitud, y varía entre los 20 centímetros de Lloroza, y más de 50 centímetros cerca del collado de la Canalona. En algunos casos, se aprecia la superposición o la ocurrencia sucesiva de al menos dos deslizamientos, como en el alud de la $\mathrm{Ca}$ - nalona (Figura 45.24, izquierda), donde se distinguen tres placas sucesivas, y dos fases en la formación de canales de escorrentía y en El Vallellón (Figura 45.24, derecha), donde aparece un depósito a media ladera y el principal en la zona baja.

Los diecinueve aludes observados, tienen una extensión de 2 ha en promedio. Si aceptamos que la placa desprendida tuviera unos 25 centímetros de espesor, y asignamos como densidad de la nieve húmeda el valor de $500 \mathrm{~kg} / \mathrm{m}^{2}$ supondría una masa de nieve movilizada, por alud, del orden de 2500 toneladas.

Se desarrollaron entre 1300 y 2400 metros de altitud, aunque tuvieron un recorrido medio de entre $100 \mathrm{y}$ 200 metros. Se ocasionaron en laderas que tienen una pendiente media de $33^{\circ}$, aunque el alud se ha extendido desde los $45^{\circ}$ a los $23^{\circ}$.
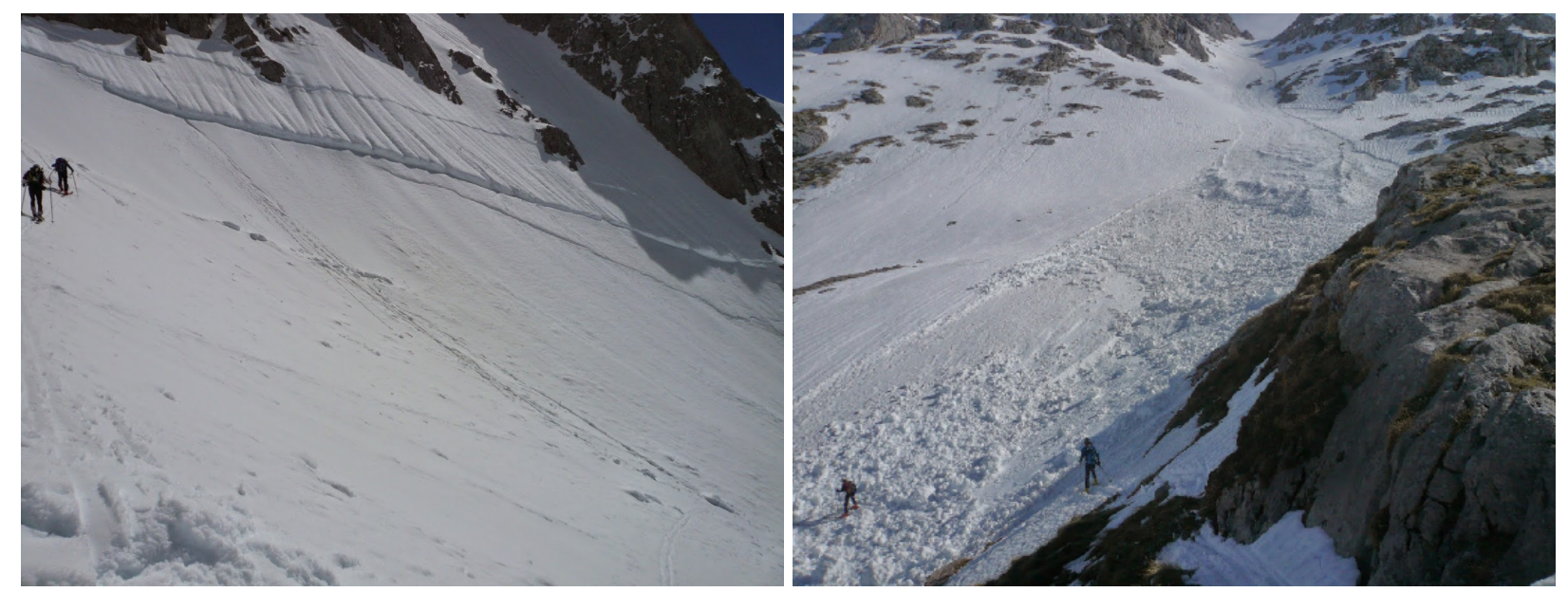

Figura 45.24: Izquierda: zona de fractura de la placa del alud de la Canalona. Se ven al menos tres planos de deslizamiento. Arriba en la imagen, se identifica el que corresponde a una placa de unos diez centímetros de altura y que se habría desprendido en primer lugar; el principal, un poco más abajo, que supera los 50 centímetros de grosor en el corte; y el tercero, que aparece como una línea oblicua desde el centro de la imagen hacia la derecha, de unos 15 centímetros de altura que se produciría al final, cuando ya la lluvia habría dejado de penetrar en el manto, no se aprecian marcas de escorrentía en el plano que queda al descubierto. Derecha: alud del Vallellón. Se aprecian dos tramos en el deslizamiento, el primero deja un depósito a media ladera, y el segundo alcanza el final de la ladera, cuyo depósito atraviesan los esquiadores. 


\subsubsection{Predicción del ECENS}

Incertidumbre y predecibilidad durante el episodio. Cinco días antes del evento, la pasada del ECENS del 23 de marzo de 2015, ofrecía unos escenarios que mostraban relativamente algo más de incertidumbre para la secuencia de días siguientes que el caso de 1996 (no se muestra por brevedad), al igual que pasaba en el segundo caso de alud y aportando, así, valor añadido al ECHRES.

Temperaturas esperadas. Igual que en el caso anterior, la Figura 45.25 muestra un mosaico de tem- peraturas mínimas previstas por ECENS, pasada 2015032300, cinco días antes del evento, para los días previos e incluyendo el del alud, en columnas los días 23, 24, 25, 26 y 27 y las filas representan los umbrales $6,4,2,0,-2,-4$ y $-6^{\circ} \mathrm{C}$. Cada pequeño mapa representa en colores la probabilidad de que la temperatura sea inferior al umbral especificado. De este modo, para la cordillera Cantábrica podemos esperar temperaturas bajo cero los 4 primeros días y un calentamiento a partir del día 26. Volvemos a insistir en la diferencia en orografía y resolución entre el ECENS de 1996 y los años 2014-2015.
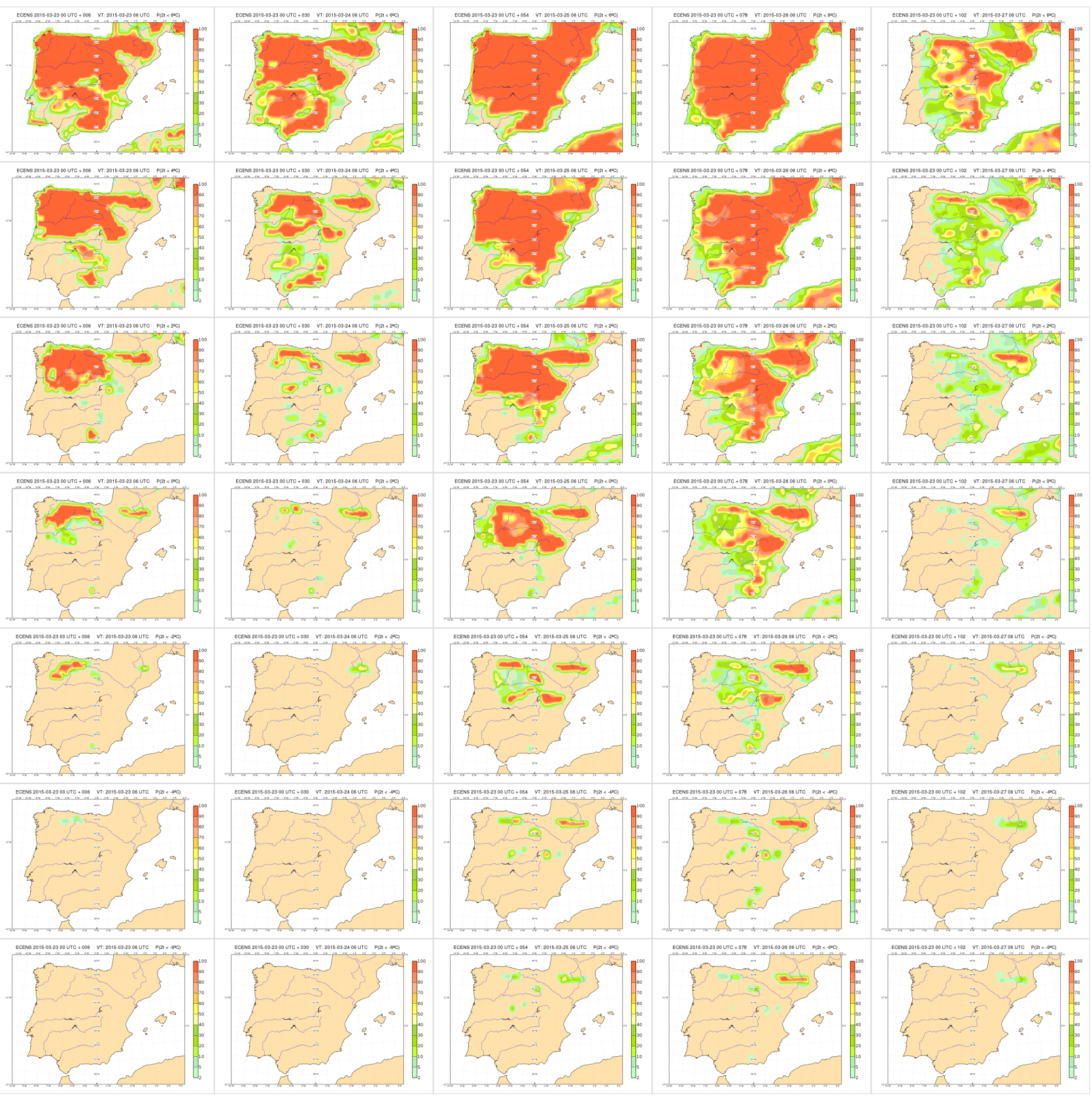

Figura 45.25: Temperaturas mínimas previstas para los días 23-03-2015 a 27-03-2015 (ver texto). 


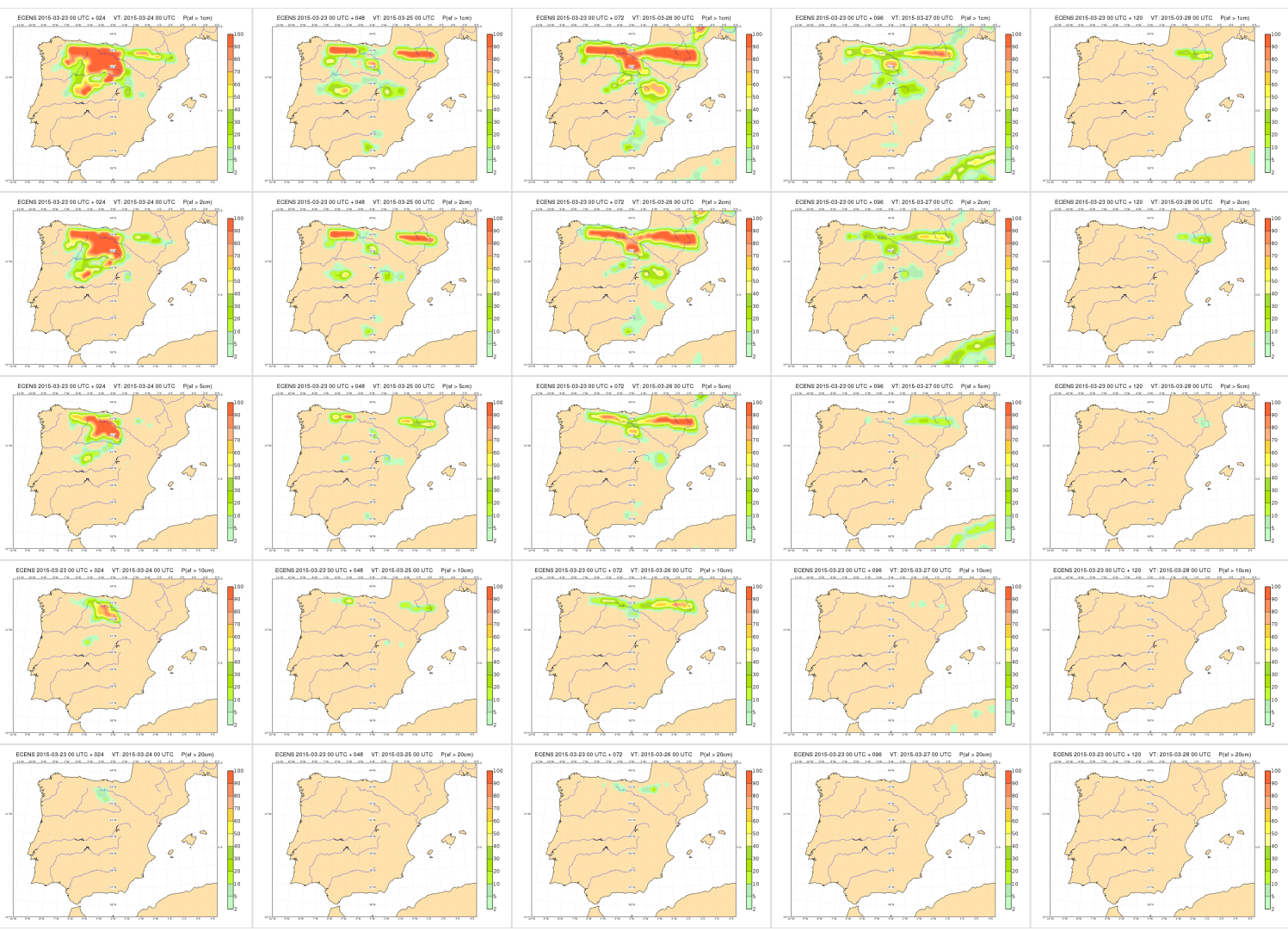

Figura 45.26: Arriba: probabilidades de nieve (00-24 UTC) estimadas por el ECENS pasada 2015032300 para el abanico de días 23-03-2015 a 27-03-2015. Las columnas representan los días 23, 24, 25, 26 y 27 y las filas los umbrales 1, 2, 5, 10 y $20 \mathrm{~cm}$ de nieve. Abajo: probabilidades de precipitación total, con umbrales de 1, 2, 5, 10 y $20 \mathrm{~mm}$.
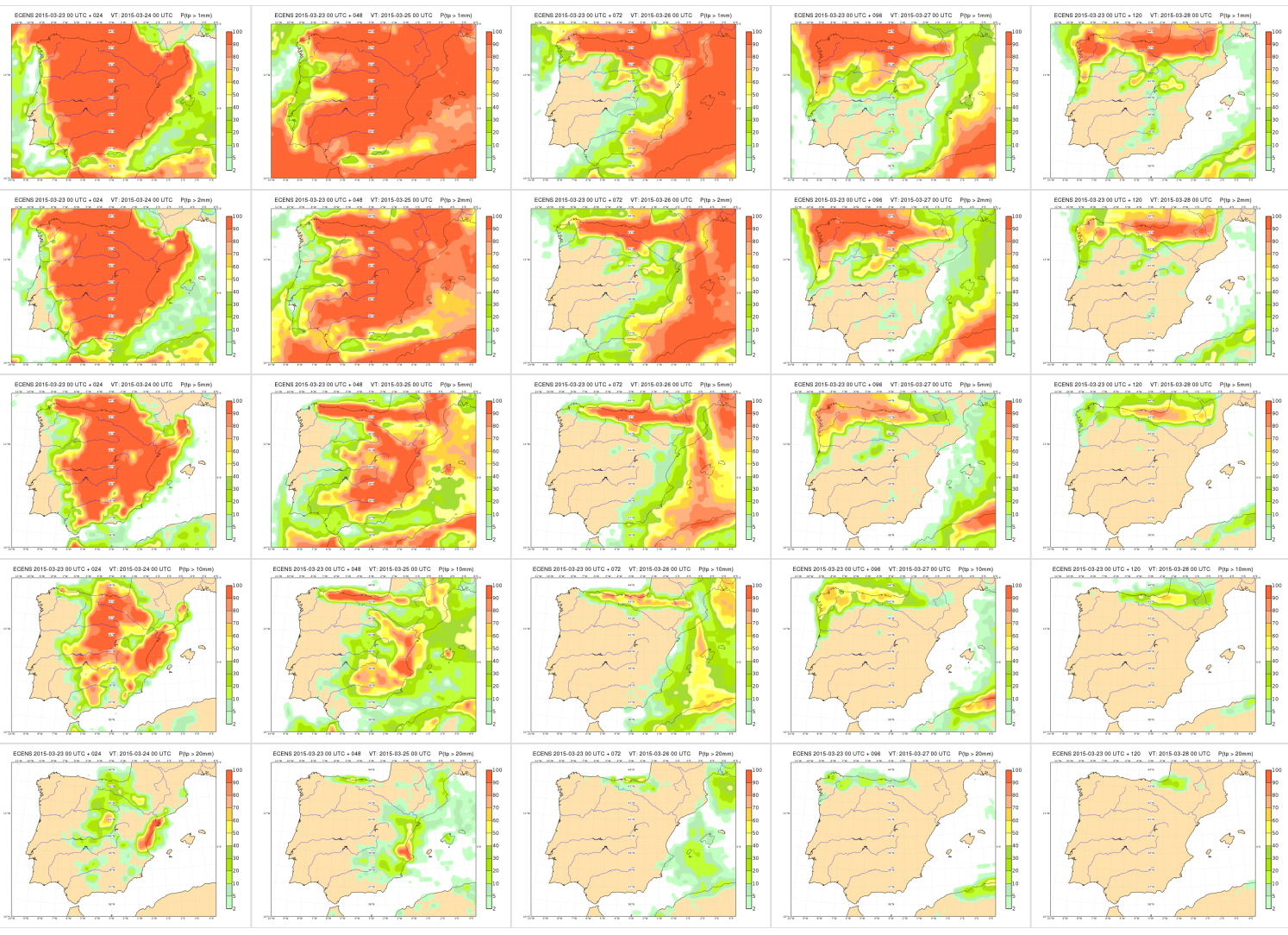
Nieve y precipitación total esperadas. En la Figura 45.26 en la página anterior se muestra la pasada del ECENS de 00 UTC del día 23 de marzo de 2015, cinco días antes del evento, la nieve prevista (arriba) y la precipitación total acumulada prevista (abajo), lluvia+nieve que, como ya se ha comentado antes, contiene tanto nieve como agua líquida. La descripción general de las características los mapas del segundo alud es la misma que en este caso. En ambas figuras las columnas representan los días 23, 24, 25, 26 y 27 y las filas los umbrales $1,2,5,10$ y $20 \mathrm{~cm}$ de nieve o mm de lluvia.

Para los días 25-26, en los que hubo considerable precipitación en forma de nieve para acumular los mantos descritos anteriormente, sí se tenía una señal consistente de probabilidad de nieve (así como en los días previos) aunque se registró algo más tarde de lo previsto: probabilidades de $60-70 \%$ de nevadas superiores a $10 \mathrm{~mm}$ el día 25 . Tras el calentamiento y subida considerable de la isocero, la precipitación registrada de $50 \mathrm{~mm}$ en forma de lluvia los días 26-27 encuentra cierta consistencia en los mapas de probabilidad de precipitación total, en los que podemos apreciar señales de probabilidad, aunque pequeña, en umbrales altos de precipitación (10 y $20 \mathrm{~mm}$ ). Tal como describíamos en el caso anterior de 2014, el ECENS puede delimitar razonablemente las zonas, aunque es difícil que levante la alerta claramente sobre un fenómeno de este tipo: no se modelizaban las acumulaciones que se dieron. Y ese, de momento, es el valor que puede esperarse de estos sistemas para prevenir este tipo de eventos. El resto viene de la experiencia y el conocimiento de los profesionales de la predicción, que seguirán siendo imprescindibles.

\subsection{Lecturas recomendadas}

Se recomienda, a modo complementario, la lectura de las siguientes obras, relacionadas con el glaciarismo y el relieve, así como las avalanchas y su predicción: [8, $9,10,14]$. 


\subsection{Referencias}

[1] Ayala CARCedo, F J. "La ordenación del territorio en la prevención de catástrofes naturales en la geografía española”. En: Boletín de la Asociación de Geógrafos Españoles 30 (2000), páginas 37-49 (citado en página 690).

[2] Bolognesi, R. "Protection du refuge de Respomuso contre les avalanches". En: Geographicalia 42 (2002) (citado en página 698).

[3] Chueca, J y col. "Mapa geomorfológico del Alto Gállego (Pirineo aragonés)". En: Boletín Glaciológico Aragonés 1 (2000) (citado en página 694).

[4] ConRAD, O y col. "System for automated geoscientific analyses (SAGA) v. 2.1. 4". En: Geoscientific Model Development 8.7 (2015), página 1991 (citado en páginas 702, 709).

[5] FRÄNZLE, Otto. Glaziale und periglaziale Formbildung im östlichen Kastilischen Scheidegebirge (Zentralspanien). Bonner Geo. 26. Bonn: F. Dümmler, 1959 (citado en página 702).

[6] Guyomarc'H, G. Les avalanches. MétéoFrance, S. Martin d'Heres, Grenoble, France, 1996 (citado en páginas 691, 692).

[7] Guyomarc'H, G. Les avalanches. Traducción del CMT de Aragón, La Rioja y Navarra. INM. INM de la traducción. MétéoFrance, CNRM CEN del original., 1996 (citado en páginas 690-692).

[8] Julián, A, Chueca, J y René, P. "El glaciarismo actual en los macizos de Balaitús e Infiernos-Punta Zarra (Pirineo Central)". En: Geografía Física de Aragón. Aspectos generales y temáticos, Univ. Zaragoza e Institución Fernando el Católico (2004), páginas 95-101 (citado en página 715).

[9] Magnusson, M M. "Recommendations for the prediction of avalanches". En: Recommendations to deal with snow avalanches in
Europe. NEDIES, Report EUR 20839 (2003), páginas 3-14 (citado en página 715).

[10] McClung, D y Schaerer, P. "Avalanchas". En: Sua Edizioak-Ediciones Desnivel 305 (1996) (citado en página 715).

[11] Palacios, D y Andrés, N. “Morfodinámica supraforestal actual en la Sierra de Guadarrama y su relación con la cubierta nival: el caso de Dos Hermanas-Peñalara". En: Procesos y formas periglaciares en la montaña mediterránea (2000). Editado por PEÑA, J L, SÁnChEZ-FABRE, M. y LoZANo, M.V., páginas 235-264 (citado en páginas 702, 703).

[12] Palacios, D y Andrés, N. "Relación entre dinámica nival y erosión en el Parque Natural de Peñalara y áreas próximas". En: Quintas Jornadas Científicas del Parque Natural de Peñalara y del Valle de El Paular (2007), páginas 95-137 (citado en página 702).

[13] Palacios, David, Andrés, Nuria de y LUENGO, Enrique. "Distribution and effectiveness of nivation in Mediterranean mountains: Peñalara (Spain)". En: Geomorphology 54.3 (2003), páginas 157-178 (citado en página 703$)$.

[14] PeÑa, J L y Lozano, M V. "Las unidades del relieve aragonés". En: Geografía Física de Aragón, Aspectos Generales Y Temáticos (2004), páginas 3-14 (citado en página 715).

[15] PeÑA, J L y col. "Mapa geomorfológico de Aragón". En: Consejo de Protección de la Naturaleza de Aragón, Zaragoza (2002) (citado en página 694).

[16] QGiS Development Team. QGIS Geographic Information System. 2009. URL: http: //qgis . org (citado en páginas 691, 694, 698).

[17] REY, L. La nieve, su metamorfosis, los aludes. MOPT, 1985 (citado en página 690).

[18] Riva, J. de la. "Caracterización climática del alto valle de Tena". En: Boletín Glaciológico Aragonés 1 (2000), páginas 81-109 (citado en página 695). 
